OPEN ACCESS

Edited by:

Zheng $L i$,

Shenzhen University, China

Reviewed by:

Tao Yu,

North Carolina State University,

United States

Hugo José Nogueira Pedroza Dias

Mello,

São Paulo State University, Brazi

*Correspondence:

Junmei Fan

jmfan@tynu.edu.cn

Liping Ding

ding/p33@snnu.edu.cn

Specialty section:

This article was submitted to

Analytical Chemistry,

a section of the journal

Frontiers in Chemistry

Received: 13 June 2020

Accepted: 14 October 2020

Published: 04 November 2020

Citation:

Fan J, Qi L, Han H and Ding L (2020)

Array-Based Discriminative Optical Biosensors for Identifying Multiple Proteins in Aqueous Solution and Biofluids. Front. Chem. 8:572234. doi: $10.3389 /$ fchem.2020.572234

\section{Array-Based Discriminative Optical Biosensors for Identifying Multiple Proteins in Aqueous Solution and Biofluids}

\author{
Junmei Fan ${ }^{1 *}$, Lu Qi ${ }^{2}$, Hongfei Han ${ }^{1}$ and Liping Ding ${ }^{2 *}$ \\ ${ }^{1}$ Department of Chemistry, Taiyuan Normal University, Jinzhong, China, ${ }^{2}$ Key Laboratory of Applied Surface and Colloid \\ Chemistry, Ministry of Education, School of Chemistry and Chemical Engineering, Shaanxi Normal University, Xi'an, China
}

Identification of proteins is an important issue both in medical research and in clinical practice as a large number of proteins are closely related to various diseases. Optical sensor arrays with recognition ability have been flourished to apply for distinguishing multiple chemically or structurally similar analytes and analyzing unknown or mixed samples. This review gives an overview of the recent development of array-based discriminative optical biosensors for recognizing proteins and their applications in real samples. Based on the number of sensor elements and the complexity of constructing array-based discriminative systems, these biosensors can be divided into three categories, which include multi-element-based sensor arrays, environment-sensitive sensor arrays and multi-wavelength-based single sensing systems. For each strategy, the construction of sensing platform and detection mechanism are particularly introduced. Meanwhile, the differences and connections between different strategies were discussed. An understanding of these aspects may help to facilitate the development of novel discriminative biosensors and expand their application prospects.

\section{Keywords: protein, sensor array, nanoparticles, amphiphilic aggregate, environment-sensitive system}

\section{INTRODUCTION}

Proteins are fundamental components of cells and tissues of human bodies, and play important roles in various life processes, such as repairing tissue, transporting substances and maintaining the normal metabolism (Zhao et al., 2016; Wang et al., 2019). Studies have reported that proteins are involved in diagnosis of various affiliated diseases including Alzheimer's, Parkinson's, Huntington's, and prion diseases (Galdeano et al., 2012; Scala et al., 2013). Abnormal protein concentration levels in biofluids (serum, urine, etc.), cells or tissues can provide necessary information for the early diagnosis of various pathological conditions (Li and Liu, 2010; Kong et al., 2011). Thus, it is of great significance to quantitatively analyze and specially recognize proteins for applications in medical diagnostics, proteomics and pathogen detection.

Among many detection methods for proteins, discriminative optical sensors have exhibited advantages like high sensitivity, high-throughput and real-time online detection, which have gained increasing attention (Zhu et al., 2015; Zhang et al., 2017; Fan and Ding, 2018). Besides, such crossreactive sensors enable the recognition of structurally or chemically similar analytes and even the identification of mixed or unknown samples (Lin et al., 2016; Bigdeli et al., 2017; Wang et al., 2018). One way to achieve discriminative sensing is to develop multi-element sensor arrays, which are 
inspired by mimicking mammalian taste and smell systems and usually consist of multiple cross-reactive elements that generate a combined recognition pattern for each analyte (Stewart et al., 2013; Peveler et al., 2016; Rana et al., 2016). Another way to realize discriminative sensing is to fabricate an environmentsensitive sensor array, which is constructed by changing the solvents (Cao et al., 2014b, 2020; Smith et al., 2019), probe concentrations ( $\mathrm{Li}$ et al., 2014), or $\mathrm{pH}$ values and ionic strengths (Liu et al., 2017; Tomita et al., 2017; Zhou et al., 2017; Lin et al., 2019). The third type of discriminative sensing is multi-wavelength cross-reactive single-system-based sensors, which use multiple wavelengths instead of multi-elements to provide response signals (Wu et al., 2011; Rout et al., 2012). During the past few decades, these three types of optical sensors, especially the first type, have been widely employed for protein discrimination.

In this review, we focus on the array-based discriminative optical biosensors for identifying proteins according to the above-mentioned three strategies. The construction principle, sensing mechanism, sensitivity and accuracy, and practical application (protein identification in serum or urine and cell or bacterium discrimination) of various sensors are particularly introduced in detail. An understanding of these aspects may facilitate the development of novel discriminative optical biosensors and expand their application prospects.

\section{MULTI-ELEMENT-BASED SENSOR ARRAYS FOR PROTEIN RECOGNITION}

The most widely adopted strategy of building sensor arrays is to use a number of cross-reactive sensors as elements to provide multiple response signals and generate recognition patterns for analytes. A variety of sensor elements like conjugated polymer, amphiphilic aggregates, nanoparticles, quantum dots, etc., have been used to generate multiple element sensor arrays for the purpose of protein identification.

\section{Conjugated Polymers}

Conjugated polymers (CPs) have been extensively explored for chemical and biological sensor design due to their highly delocalized electronic structures and unique optical and electronic properties (Chen et al., 2013; Zhao et al., 2017). The delocalized structures of $\mathrm{CP}$ backbones allow efficient intraand inter-chain energy transfer that amplifies signals by the collective response compared with small molecule-fluorophores. Their optical properties (absorption and emission) are sensitive to minor conformational or environmental variations, enabling efficient detection of subtle differences when bound with various analytes in sensing processes. Water-soluble CPs with hydrophobic backbones and hydrophilic side-chains or ionic units can associate with different proteins through multivalent interactions, producing unique optical responses to different proteins (Feng et al., 2010).

Based on the non-specific interaction between conjugated polymers and proteins, Miranda et al. (2007) reported using six functionalized poly( $p$-phenyleneethynylene)s (PPEs) to create

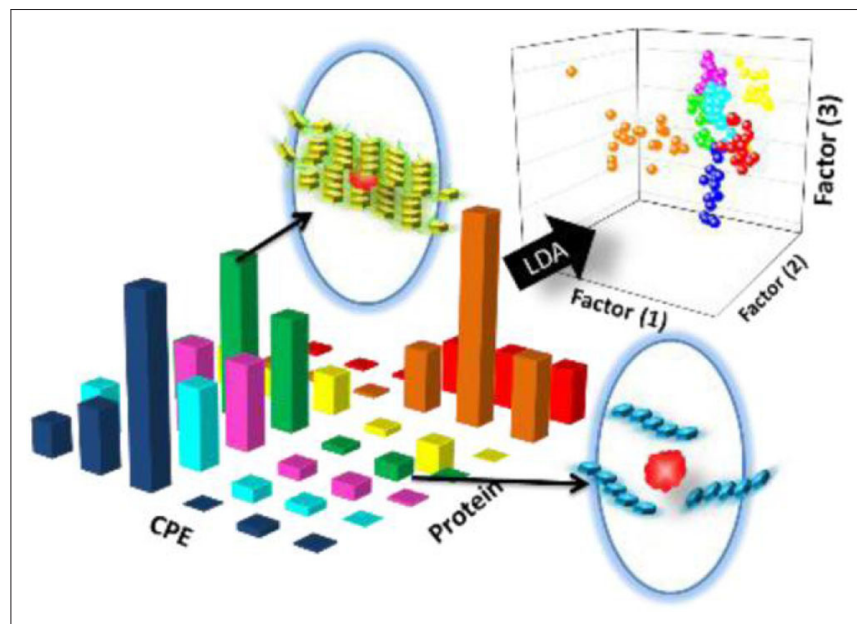

FIGURE 1 | Schematic representation of the CPEs-based sensor array for the discrimination of proteins. Reprinted from Wu and Schanze (2014) with permission.

a six-element sensor array for identifying 17 proteins which have diverse molecular weight, metal/non-metal-containing, isoelectric point (pI), and UV absorbencies. LDA results illustrated that the tested 17 proteins could be well-clustered into 17 different groups with a classification accuracy of $100 \%$. Moreover, out of the 68 protein samples randomly selected from 17 proteins, only two samples were misclassified, and the identification accuracy was $97 \%$. This work demonstrated that a PPE-based sensor array could effectively detect and distinguish proteins.

$\mathrm{Wu}$ and Schanze (2014) constructed a fluorescent sensor array containing six conjugated polyelectrolytes (CPEs) and explored the aggregation state/size change upon binding with a set of different proteins by fluorescence correlation spectroscopy (Figure 1). This CPEs-based array could well identify seven proteins and successfully discriminate unknown protein samples with an accuracy of $93 \%$ by LDA. They found that the charge type (cation and anion) of CPEs played the most important role in protein recognition compared to other factors, such as charge density, molecular weight, and backbone structure. This kind of probes can be optimized by increasing the purity of polymers, conjugating more diverse functional groups to backbones or introducing novel CPE probes. Importantly, one of the challenges of this type of sensors is the need to eliminate potential interference when used for detection in complex biological environments.

\section{Amphiphilic Aggregates}

As we all know, amphiphilic molecules, such as surfactants, dendrimers, and block copolymers can form dynamic supramolecular aggregates, such as micelles and vesicles in aqueous solutions (Yan et al., 2010, 2012). The strategy of amphiphilic aggregates encapsulating and modulating fluorophores has been widely applied in construction of fluorescent sensors or arrays for proteins because they can 
provide several advantages: (1) The hydrophobic domains can non-covalently encapsulate guest probes to improve their solubility, fluorescence stability and quantum yield ( $\mathrm{Hu}$ et al., 2010; Geng et al., 2014; Fan et al., 2019). (2) The subtle variation of amphiphilic molecule aggregation states can modulate the photophysical properties and fluorescence emission of encapsulated probe (Ding et al., 2013; Cao et al., 2014a; Cao J. et al., 2014). Thus, protein-caused aggregation changes of amphiphilic assemblies can further induce fluorescence variation for detecting proteins.

Using this strategy, Thayumanavan et al. have developed simple methods for constructing sensor arrays for protein recognition by using one kind of amphiphilic aggregates to encapsulate different fluorophores (Sandanaraj et al., 2007; Gonzalez et al., 2009) or using different types of amphiphilic aggregates to encapsulate one fluorophore (Savariar et al., 2008). At first, they used a single amphiphilic polymer-based micellar host to encapsulate eight different hydrophobic dyes in its micellar interior and prepared an eight-element sensor array for distinguishing metalloproteins (Sandanaraj et al., 2007). Each ensemble showed different quenching responses to the four target metalloproteins and could generate a distinct recognition pattern by collecting the quenching signals (Figure 2A). Later, they fabricated a four-element sensor array using a negatively-charged surfactant and positively-charged polyelectrolyte formed micelle to encapsulate four dyes for discrimination of eight different proteins (Gonzalez et al., 2009). As shown in Figure 2B, protein-polyelectrolyte binding interaction could disassemble the supramolecular assembly, which released the guest dyes from the assembly interior. The different binding affinity between various proteins and polymer could produce distinct recognition patterns for protein discrimination. The main advantage of the present approach is that it is easy to construct a fluorescent sensor array by simple interchange of fluorophores, which spares time-consuming design and synthesis of multiple receptors. In addition, they also used different combinations of polyelectrolyte-surfactant assembly to encapsulate the same dye to build multipleelement sensor array for successfully distinguishing 5 proteins (Savariar et al., 2008). In 2018, Li et al. also demonstrated that the encapsulation of quantum dots-fluorophore FRET pair in different surfactant-polyelectrolyte nanomicelles could provide an efficient cross-reactive sensor for serum proteins (Li et al., 2018). Due to the completely non-covalent nature of the receptor component, the simplicity of the design makes this method highly versatile.

Choi et al. (2018) designed and synthesized four watersoluble aggregation-induced emission luminogens (AIEgens), which showed strong fluorescence upon addition of proteins by restricting the intramolecular rotation of AIEgens. The AIEgenprotein affinity was related to different chemical functional groups on AIEgens, which results in distinct fluorescence variations for each protein. The combined fluorescence outputs enabled accurate classification of five different proteins and specific proteins at different concentrations by LDA. This study provides a novel strategy for protein discrimination using amphiphilic fluorescent AIEgens as sensor elements.

\section{Quantum Dots}

Quantum dots (QDs) are fluorescent materials which possess advantages like high fluorescence quantum yields, narrow and symmetric emission band, broad absorption, high resistance to photobleaching, large "effective" Stokes shifts, versatile surface modification, etc. (Boeneman et al., 2010; Tyrakowski and Snee, 2013; Zhang Z. et al., 2015) These unique properties make them useful for multiplexing in biological assay, such as long-term biological imaging (Jaiswal et al., 2003; Chen and Gerion, 2004), optical coding of cells (Gao et al., 2002; Mattheakis et al., 2004), diagnostic tools for cancer, etc. (Bakalova et al., 2004; Michalet et al., 2005; Mansur et al., 2014) Thus, QDs have emerged as attractive semiconductor materials in chemo/biosensing over the past few decades (Heuff et al., 2007).

QDs can form conjugates with ionic liquids or nanoparticles for constructing protein sensor arrays. Chen et al. (2015) reported that the introduction of QDs could improve the sensing sensitivity and discrimination accuracy of the ionic liquid-based sensor arrays due to the high quantum yields of QDs. They first constructed a sensor array containing five different ionic liquids (BBimCl, EEimBr, BBimBr, $\mathrm{HHimBr}$, and OOimBr) and found it is difficult to distinguish 8 proteins at $500 \mathrm{nM}$ completely (with an accuracy of $91.7 \%$ ) (Figures 3A,B). Because the weak fluorescence of some ionic liquids limited the performance of this sensing system, they then employed CdTe quantum dots with strong fluorescence emission to form conjugates with ionic liquids and developed a new sensor array (BBimCl@CdTe, EEimBr@CdTe, BBimBr@CdTe, HHimBr@CdTe, and CdTe) to improve its recognition ability (Figure 3C). In this case, ionic liquids function as the main receptors to interact with proteins through hydrophobic and electrostatic interactions. CdTe QDs function as the main reporters and can also interact with proteins and lead to fluorescence variation because of the diminishing of surface defects. This sensor array can achieve the discrimination of proteins $(\mathrm{LOD}=10 \mathrm{nM})$, protein mixtures, six physiologically relevant proteins spiked in human urine, and six strains of bacteria from three different species with 100\% accuracy. Such an array system can be used as an easy-to-access, highly differentiated and adaptive tool for high-precision discrimination of biological targets. It also provides a novel method for the construction of sensitive sensor arrays for biological or diagnostic purposes.

Wang et al. (2017) developed a simple nanoparticle-quantum dot-based sensor array using six different nanoparticles and a single CdSe QDs, where nanoparticles serve as receptors and QDs as indicators. Fluorescence turn-on or further turn-off occurred because of the disruption between nanoparticles and QDs by proteins, creating distinct response patterns. LDA illustrated this array could well discriminate eight proteins and six cancer cells. This work indicates that the combination of nanoparticles and QDs offers arrays great potentials for medical diagnostics in future.

QDs can also be modified with different ligands to distinguish proteins. Chang et al. (2016) synthesized four dualemitting Mn-doped ZnS QDs decorated with different functional ligands (MPA, TG, GSH, and NAC) as sensor elements for 


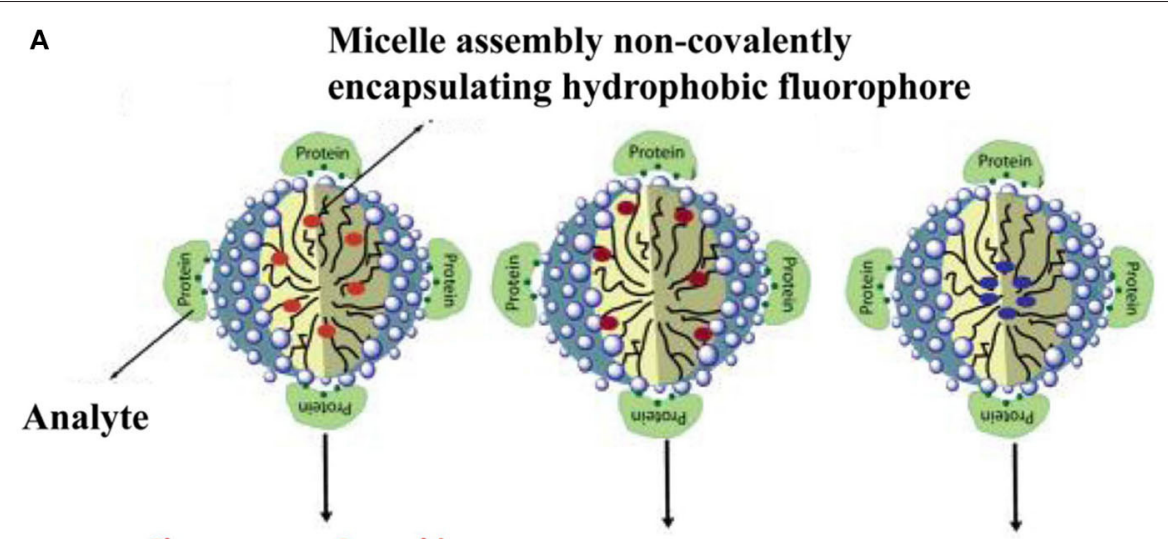

Fluorescence Quenching Fluorescence Quenching Fluorescence Quenching Response \# 1

Response \# 2

Response \# 3

B

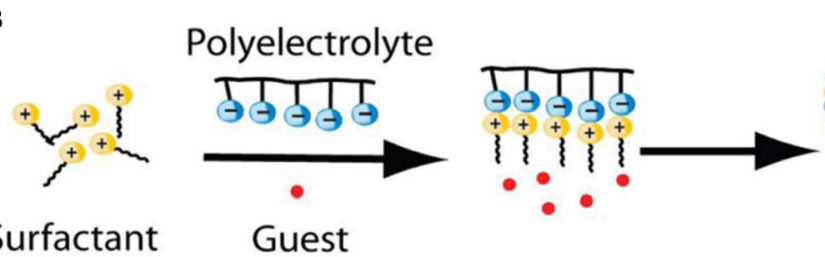

Surfactant

Guest
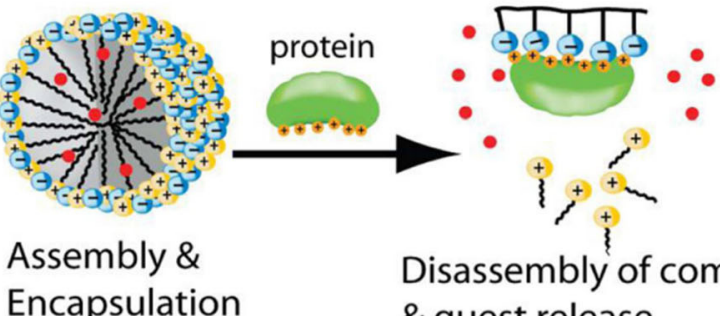

Disassembly of complex $\&$ guest release

FIGURE 2 | Schematic representation for protein recognition: (A) A single amphiphilic polymer encapsulated different dyes and (B) A surfactant-polyelectrolyte ensemble encapsulated different dyes. Reprinted from Sandanaraj et al. (2007) and Gonzalez et al. (2009) with permission.

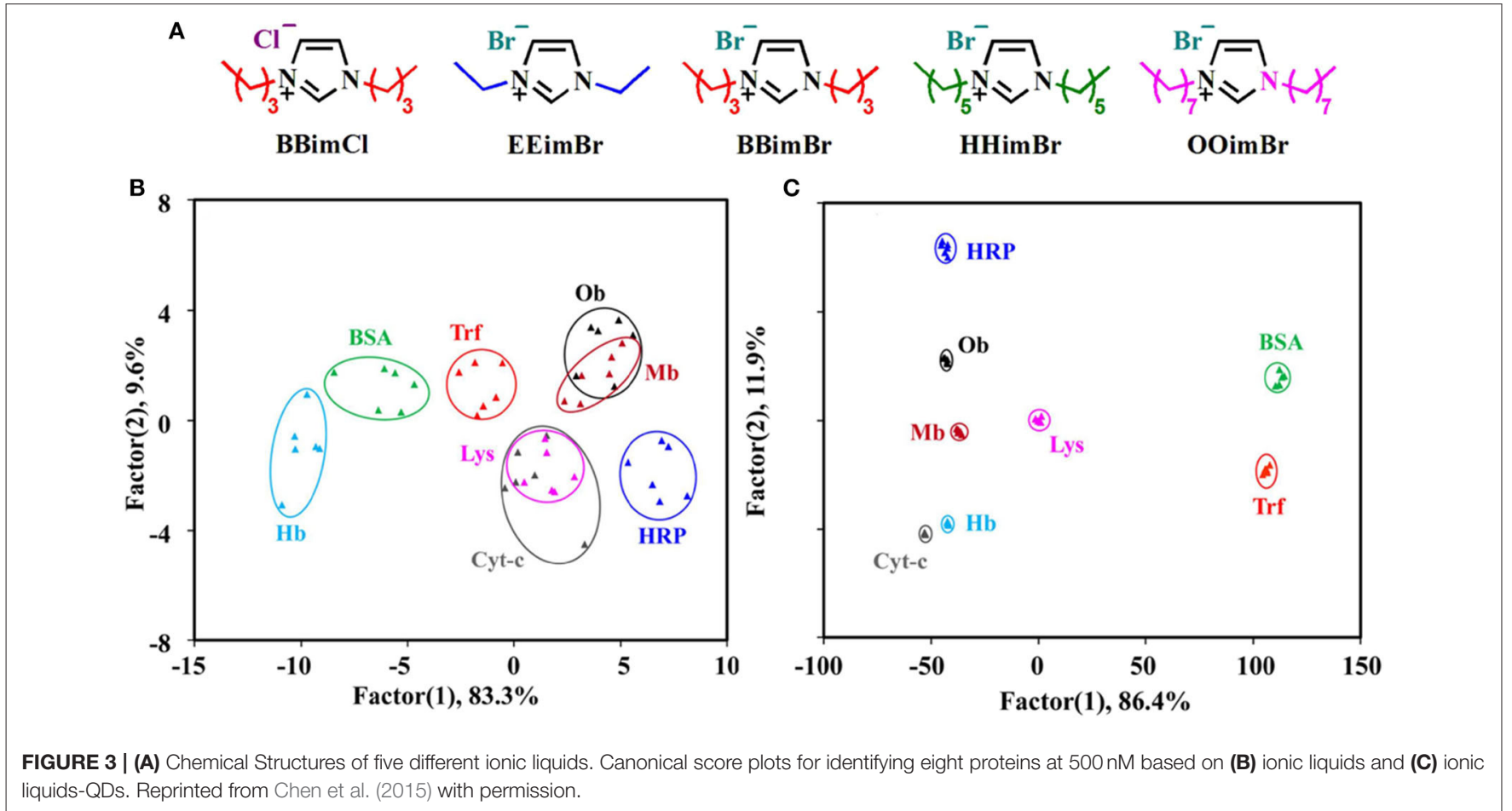


recognizing proteins (Figure 4). This ratiometric sensor array can discriminate pure proteins, unknown samples, and proteins in human urine with a high accuracy. Meanwhile, the authors found that the ratiometric signal can not only improve the recognition ability of sensor arrays, but also eliminate effectively the signal interference from $\mathrm{pH}$ changes. This research will open up new avenues to improve the discrimination capability of sensor arrays.

\section{Gold Nanoclusters}

Gold nanoclusters (Au NCs) are composed of several to hundreds of gold atoms, which have gained great attention due to their ultra-small size, excellent biocompatibility and unusual photophysical properties (Lin et al., 2018; Xie et al., 2018). A large number of protected materials including polymers, proteins, peptides and DNA have been applied for preparing fluorescent Au NCs (Kong et al., 2012; Kwak et al., 2014; Zhang J. et al., 2015). And fluorophore-functionalized Au NCs have attracted much attention for protein recognition.

Xu et al. (2014) developed a visual sensor array composed of two blue-emitting collagen or macerozyme $\mathrm{R}-10$ protected $\mathrm{Au}$ NCs (Col-Au NCs and Mac-Au NCs) for pattern recognition of eight proteins. Experiment results illustrated that the possible mechanism was attributed to the protein-Au NCs complex formation. Furthermore, the present colorful array could effectively discriminate the serums from healthy people, hepatoma patients and thalassemia patients due to the different contents of certain proteins, showing potential application in clinical diagnosis (Figure 5). The same group also fabricated a sensor array based on five protein-protected Au NCs for protein discrimination, which was different from the traditional fluorescent sensor arrays due to the unexpected emission induced by luminol solution (Sun et al., 2017). This sensor array could identify seven proteins, because the added different proteins might have interactions with capping proteins on Au NCs, which further influenced the catalysis role of Au NCs on luminol emission. This research not only offers new insights of Au NCs into the emission of luminol, but also shows the potential for protein recognition.

In addition, Xu et al. (2017) built a protein sensor array based on six near infrared fluorescent amino acid-functionalized $\mathrm{Au}$ NCs containing two ligands, which have similar fluorescence profiles but different surface properties. These Au NCs could interact with proteins through hydrogen bonding and van der Waals forces, and the array could successfully distinguish ten proteins. More importantly, serums from three stages (early, middle, and late) of breast cancer patients and healthy individuals could also be identified, suggesting the potential applications in diagnosis of breast cancer.

\section{Gold Nanoparticles}

Gold nanoparticles (AuNPs) have been extensively applied in biosensors because of their unique optical, catalytic, chemical and electronical properties, and these properties can be modulated by changing the shape, size, surface modification or aggregation state of AuNPs (Daniel and Astruc, 2004; Zhang et al., 2020). AuNPs are usually used to combine with DNA (Lu et al., 2013b;
Sun et al., 2015), fluorophores (You et al., 2007; Bajaj et al., 2009; Rana et al., 2012), enzymes (Miranda et al., 2010), or surfactants (Rogowski et al., 2016; Xi et al., 2018) to construct non-specific protein sensor arrays.

\section{DNA-Gold Nanoparticle Conjugates}

Researchers have built lots of DNA-AuNP conjugates-based arrays for protein identification due to the different interactions among proteins, DNA and AuNPs. Besides, DNA as a nonspecific receptor could provide unlimited sensor elements for array sensing, because a short DNA sequence (e.g., 15 bases) has up to billions of combinations (Wei et al., 2017). In 2013, Lu et al. used three aptamer (DNA)-protected AuNPs as a colorimetric sensor array for protein discrimination (Lu et al., 2013b). They found that different proteins could make the DNA-AuNPs exhibit distinct aggregation behaviors in the presence of salt, causing different color change by naked eyes (Figure 6). LDA results illustrated that this sensor array could not only well distinguish seven proteins, but also identify human cancer cells and normal human cell with $100 \%$ accuracy. Similarly, Sun et al. (2015) built a protein sensor array containing three different DNAAuNPs prepared by absorbing non-specific dye-labeled DNA sequences onto AuNPs. The added proteins could remove DNA from the surface of AuNPs because of the competitive binding, resulting in "turn-on" signals of the fluorescent dye and red-toblue color changes due to the aggregation of AuNPs caused by salt. Both the fluorescent and colorimetric signals were used for identifying proteins, and this array could not only distinguish 11 proteins, but also discriminate bovine serum albumin (BSA) and human serum albumin (HSA) at different concentrations and the mixture with various ratios with an accuracy of $100 \%$ by LDA. Moreover, 10 proteins at the concentration of $1.0 \mu \mathrm{M}$ could be well-discriminated in human urine.

Later, Wei et al. (2017) used three SH-labeled DNA functionalized catalytically active AuNPs as sensor elements for protein discrimination and found that the DNA-protein interactions could mask the surface of AuNPs, which further induced the poor catalytic performance of gold nanoparticles to the reaction between 4-nitrophenol and $\mathrm{NaBH}_{4}$. The colorchange time of the reaction solution from yellow to colorless was taken as signal readout, and colorimetric response patterns could be obtained from this array. Eleven proteins even at $30 \mathrm{nM}$ have been well-distinguished by LDA and naked eyes. Remarkably, the present array was able to completely identify among individual proteins and protein mixtures at different molar ratios. Besides, the practicability of this colorimetric array was demonstrated by discrimination of 11 proteins spiked in human serum with $100 \%$ accuracy.

In addition, Yang et al. (2013) developed a AuNPsbased colorimetric sensor array including five DNA-decorated catalytic AuNPs and one bare AuNPs for protein recognition. Each protein was first mixed with the sensing platform, and then $\mathrm{HAuCl}_{4}$ and $\mathrm{NH}_{2} \mathrm{OH}$ were added to make the nanoparticles grow. They selected three wavelengths related to the particle properties for each sensor element as absorbance data acquisition. This label-free 18-dimensional array (six sensor elements $\times$ three wavelengths) could effectively distinguish 

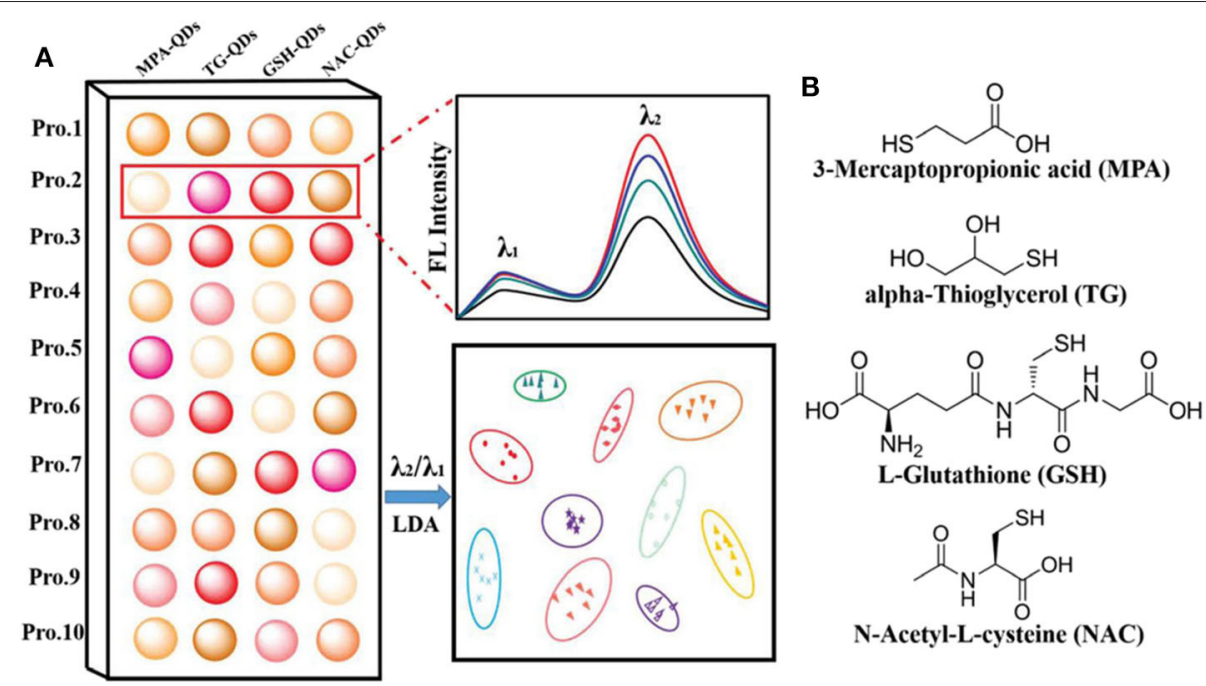

N-Acetyl-L-cysteine (NAC)

FIGURE 4 | (A) Schematic illustration of the ratiometric sensor array based on various functionalized QDs for protein discrimination. (B) Chemical structures of the four ligands modified on the surface of QDs. Reprinted from Chang et al. (2016) with permission.

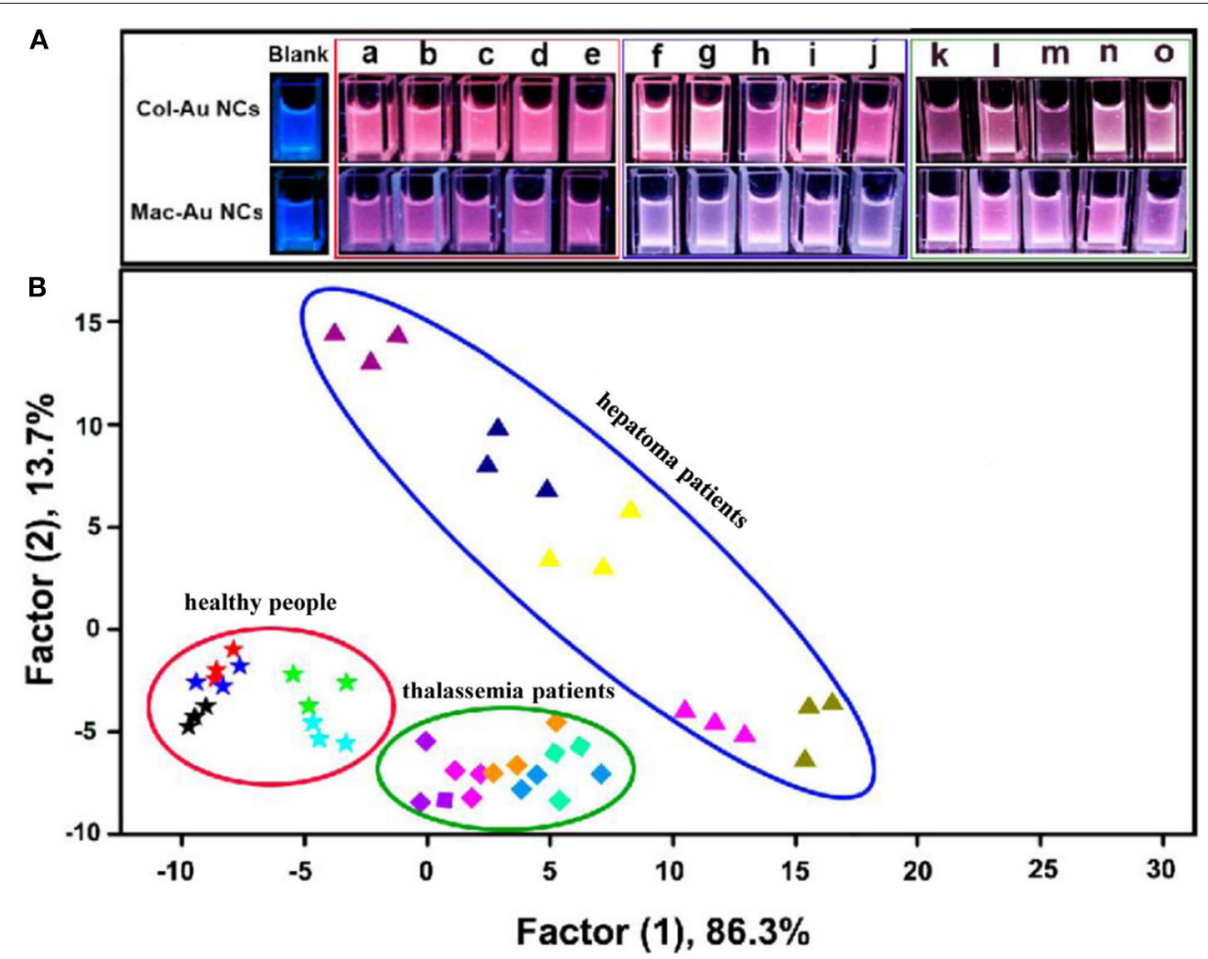

FIGURE 5 | (A) Photographs of the Au NCs in the absence and presence of human serums from five normal people (a-e), five hepatoma patients (f-j), and five thalassemia patients $(\mathrm{k}-\mathrm{O})$ under UV lamp. (B) LDA score plot for discriminating different human serums. Reprinted from Xu et al. (2014) with permission.

six different proteins, various concentrated proteins, protein mixtures and even samples in serum and urine. Later, they also used this type of sensor array to distinguish 4 different cell lines (Yang X. et al., 2014). In this type of sensor arrays, the addition of proteins can change the aggregation behaviors of DNA-AuNPs, remove DNA from AuNPs, or affect the catalytic performance of AuNPs. This protein detection method is simple, sensitive, and label-free, and it will provide new directions of developing array-based sensing systems and broaden the application field of nanoparticle-based sensors. 


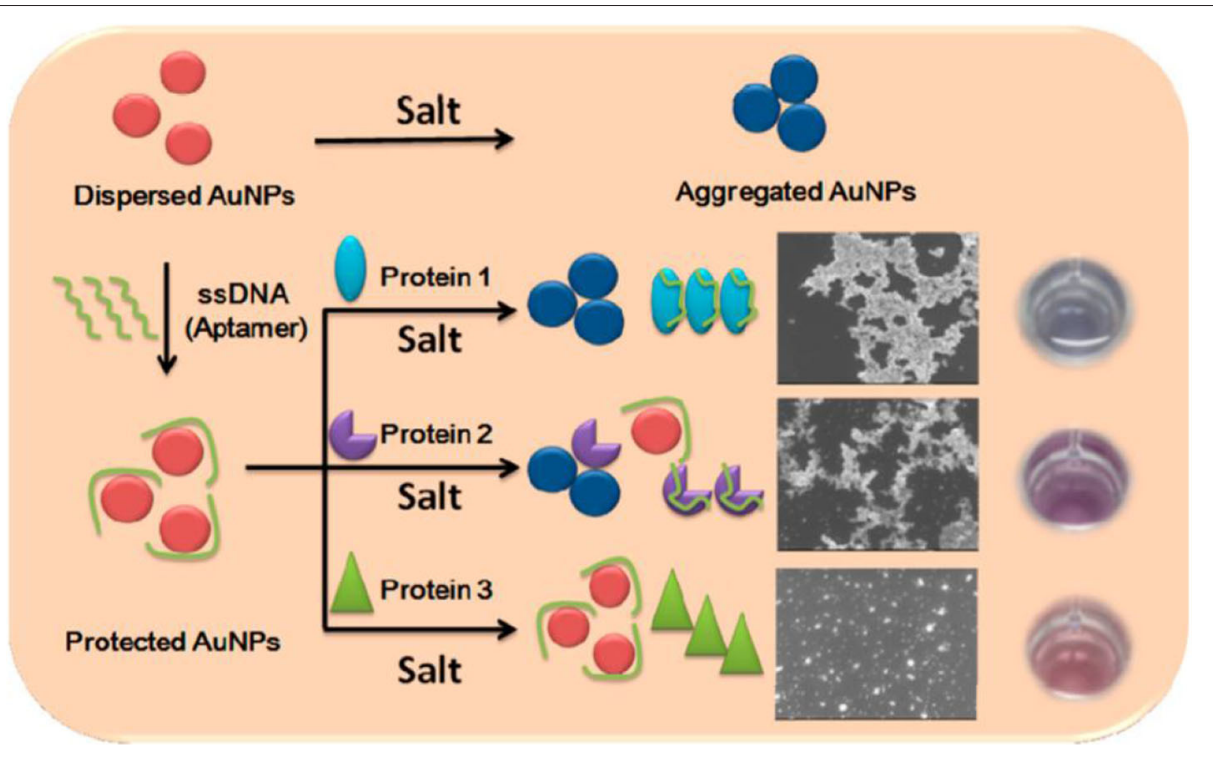

FIGURE 6 | Schematic representation of the sensing principle of the aptamer-based sensor array. Reprinted from Lu et al. (2013b) with permission.

\section{Fluorophore/Enzyme-Gold Nanoparticle Conjugates}

Rotello et al. have used different positively-charged AuNPs and one negatively-charged fluorescent polymer conjugate, green fluorescent protein (GFP), or enzyme to develop several fluorophore/enzyme displacement sensor arrays. In 2007, they developed a sensor array based on six different non-covalent cationic AuNPs and an anionic fluorescent polymer conjugate (You et al., 2007). The fluorescence of polymer conjugates was quenched by AuNPs, and this platform showed distinct turnon response patterns to different proteins because the target proteins disrupted the interaction between AuNPs and polymer conjugates. This array could not only quantitatively differentiate seven proteins at nanomolar concentrations, but also identify 52 unknown protein samples with an identification accuracy of $94.2 \%$ by LDA. Using this strategy, they developed another arraybased sensing system containing three AuNP-polymer conjugates to effectively differentiate normal, cancerous, and metastatic cells (Bajaj et al., 2009).

They also fabricated another effective sensor array containing five different positively-charged AuNPs and one negativelycharged GFP for protein recognition in buffer and human serum, where the fluorescence of GFP was quenched by AuNPs (De et al., 2009). The utilization of GFP instead of conjugated polymers minimizes the aggregation of sensor elements because GFP possesses lower aggregation than CPs, which enhances the quantum yield and sensitivity and then improves sensor efficiency. The addition of target serum proteins competed with GFP to bind AuNPs, leading to the fluorescence lightup or further quenching. It could discriminate 5 proteins at physiologically relevant concentrations in buffer (100\% accuracy) and in human serum (97\% accuracy). Furthermore, this array was also able to distinguish proteins at different concentrations, as well as the mixture of various proteins in human serum. This sensing strategy based on GFP-NP conjugates was further employed for rapidly identifying healthy and metastatic cancer cells and tissues, relying on the phenotypic differences of their overall proteome signatures (Bajaj et al., 2010; Rana et al., 2012). Notably, this eight-element sensor array created a distinct fingerprint for four normal and four metastatic tumor tissues and showed good discrimination ability. Overall, this sensing strategy provides the application prospect of unbiased phenotypic screening of tissue status caused by genetic variation and differentiation states.

In addition, they also constructed an enzyme-AuNP sensor array to improve the sensitivity through enzymatic catalysis (Miranda et al., 2010). In this approach, six AuNPs with positive surface charges were electrostatically bound to an anionic enzyme ( $\beta$-galactosidase), inhibiting the activity of enzyme. The added target proteins released the enzyme, which restored activity and turned on the fluorescence of fluorogenic substrate. This signalamplified sensor array was able to identify nine proteins at $1 \mathrm{nM}$ in both buffer and desalted human urine.

The sensing mechanism of this type of sensor array is AuNPs could quench the fluorescence of polymer conjugates or GFP, or inhibit the activity of enzyme which turn off the fluorescence of fluorogenic substrate. Various proteins have different abilities to replace fluorophores/enzymes from AuNPs, thereby generating distinct turn-on signals, and then realizing the identification of proteins and cells. Using this strategy, the Rotello group has made outstanding contributions to the protein discrimination in human serum or urine and the identification of cells including healthy, cancerous, and metastatic cells.

\section{Surfactant-Gold Nanoparticle Conjugates}

Colorimetric sensor arrays have been constructed for protein recognition by efficient surfactant-based AuNPs. Surfactants 
used in this strategy have the following advantages: (1) they can change the zeta potential of AuNPs; (2) they can act as protein receptors; and (3) they can adjust the proteininduced aggregation of AuNPs. Using a very simple washing procedure, Rogowski et al. (2016) prepared three stable AuNPs in cationic cetyltrimethylammonium bromide (CTAB), nonionic Tween 20, and anionic sodium dodecyl sulfate (SDS) to fabricate a colorimetric sensor array for differentiating five proteins. The three types of surfactants not only changed the zeta potential of AuNPs, but also modulated the adsorption-driven aggregation of AuNPs by proteins. Moreover, the sensitivity could be altered by varying the surfactant concentration and the surfactant-coated AuNPs could be used to study the interactions between NPs and other analytes. Similarly, Xi et al. (2018) built a colorimetric sensor array for protein discrimination using cationic CTAB and two cationic polymers (chitosan and polydiallyl dimethylammonium chloride) as protein receptors and AuNPs as signal transducers. Positively charged polymers could bind to AuNPs in the absence of proteins, resulting in aggregation of AuNPs. The presence of negatively charged proteins caused different degrees of AuNP aggregation due to the diverse electrostatic interactions between proteins and polymers, giving rise to different signal variations. It could well differentiate seven negatively-charged proteins in Tris- $\mathrm{HCl}$ buffer and human serum samples. Such gold nanoparticle conjugates are easy to prepare because surfactants are commercially available. But so far, this type of sensor array is limited to colorimetric sensor arrays.

\section{Other Nanoparticles}

The unmodified noble metal nanoparticles, other metal nanoparticles and nanodots are also receiving extensive attention in the field of protein sensing. Zhang S. et al. (2015) fabricated a colorimetric sensor array utilizing seven unmodified noble metal nanoparticles (2 AgNPs and 5 AuNPs) with different sizes (Figure 7). The absorbance of the nanoparticles changed differently in the presence of ten proteins, which produced distinct response patterns visually distinguished by naked eyes. These proteins at different concentrations could be further successfully identified by LDA. Moreover, this array was able to discriminate seven bacteria and four cancer cells correctly. This assay illustrated that the sensor array based on unmodified noble metal nanoparticles has application potential in medical diagnostics.

Kong et al. (2011) constructed a sensitive and effective colorimetric sensor array based on catalytically active $\mathrm{Fe}_{3} \mathrm{O}_{4}$ NPs for protein discrimination. By altering the surface functionality, the two-element array (dopamine- $\mathrm{Fe}_{3} \mathrm{O}_{4} \mathrm{NPs}$ and trimethylammonium- $\mathrm{Fe}_{3} \mathrm{O}_{4} \mathrm{NPs}$ ) was able to identify 10 proteins, and differentiate unknown samples with an accuracy of $95 \%$. Nandu et al. (2018) reported a five-element sensor array containing two-dimensional nanoparticles (2D-nps, including $\mathrm{MoS}_{2}, \mathrm{WS}_{2}$, and $\mathrm{nGO}$ ) and fluorescently labeled ssDNA after a careful screening/filtering process. The displacement of ssDNA from the surface of $2 \mathrm{D}$-nps made the array able to discriminate seven proteins.

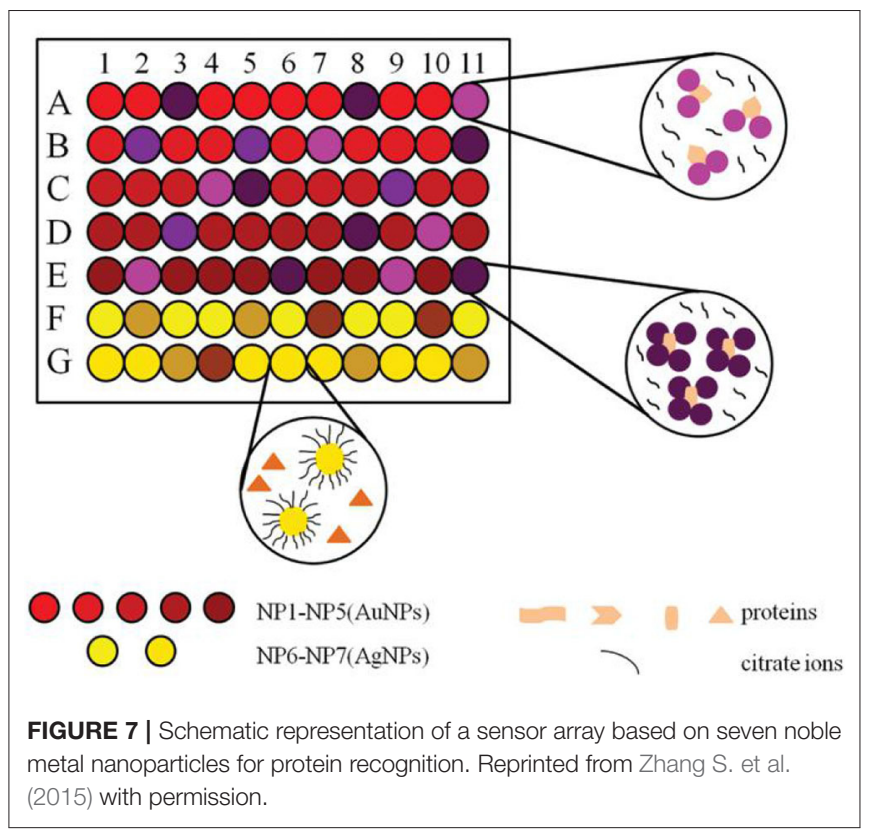

Tao et al. (2014) used seven luminescent nanodots and graphene oxide (GO) to create a protein sensor array. The fluorescence of these nanodots was quenched by GO, and the presence of various proteins disrupted the nanodotGO interaction to different extents. LDA was applied to successfully identify 10 proteins at nanomolar concentrations and discriminate 50 unknown samples with $94 \%$ accuracy. Furthermore, this array could be expanded to distinguish nonresistant and drug-resistant bacteria which express different proteins, endowing the potential applications in diagnosis of bacterial infections. Besides, Yuan et al. (2015) synthesized eight dual-ligand co-functionalized gold nanodots (Au NDs) with diverse surface and similar fluorescence properties to fabricate a sensor array for proteins, which could well discriminate eight proteins and 48 unknown protein samples (100\% accuracy). Clearly, nanoparticle-based sensor arrays are not limited to gold nanoparticles.

To construct a successful array-based optical sensing system, analytes and cross-reactive sensor elements should possess different interactions that lead to distinct responses. Multielement-based sensor arrays for proteins have been widely developed and the detection mechanism, advantages and disadvantages for different types of arrays are summarized and analyzed in Table $\mathbf{1 .}$

\section{ENVIRONMENT-SENSITIVE SENSOR ARRAYS FOR PROTEIN RECOGNITION}

Environment-sensitive sensors are a type of sensors that are dependent on the physical and chemical properties of the surrounding environment. It is relatively easy to fabricate an environment-sensitive sensor array because it can be achieved by adjusting polarity, viscosity, pH, etc. (Vazquez et al., 2005; Yang Z. et al., 2014; Daly et al., 2017) Discriminative optical 
TABLE 1 | Summary of different types of multi-element-based sensor arrays.

\begin{tabular}{|c|c|c|c|}
\hline Type & Detection mechanism & Advantages & Disadvantages \\
\hline Conjugated polymers & $\begin{array}{l}\text { The formation of protein-CP complexes causes } \\
\text { aggregation/size changes of CPs. }\end{array}$ & $\begin{array}{l}\text { The direct interaction between CPs and } \\
\text { proteins makes the array very sensitive. }\end{array}$ & $\begin{array}{l}\text { The synthesis and purification of CPs is } \\
\text { complicated. }\end{array}$ \\
\hline Amphiphilic aggregates & $\begin{array}{l}\text { Non-metalloprotein-binding induces the } \\
\text { amphiphilic ensemble disassembly or } \\
\text { assembly, and energy/electron transfer occurs } \\
\text { from the probe to metalloproteins. }\end{array}$ & $\begin{array}{l}\text { It is easy to fabricate such arrays by } \\
\text { changing the encapsulated fluorophores } \\
\text { or amphiphilic aggregates. }\end{array}$ & $\begin{array}{l}\text { The amphiphilic molecule used needs to } \\
\text { be charged and there are few fluorescent } \\
\text { amphiphilic aggregates for protein } \\
\text { recognition. }\end{array}$ \\
\hline Quantum dots & $\begin{array}{l}\text { The added proteins can disrupt the interaction } \\
\text { between QDs and ionic liquids or QDs and } \\
\text { nanoparticles. }\end{array}$ & $\begin{array}{l}\text { It can improve the sensing sensitivity and } \\
\text { discrimination ability of arrays due to their } \\
\text { high quantum yields. }\end{array}$ & $\begin{array}{l}\text { The interaction between QDs and proteins } \\
\text { is not clear, which limits the construction } \\
\text { of arrays that only use QDs for protein } \\
\text { identification. }\end{array}$ \\
\hline Gold nanoclusters & Protein-Au NCs complex is formed. & $\begin{array}{l}\text { This type of array has ultra-small size, } \\
\text { excellent biocompatibility, etc. }\end{array}$ & $\begin{array}{l}\text { Gold is a precious metal, which makes the } \\
\text { preparation of Au NCs expensive. }\end{array}$ \\
\hline Gold nanoparticles & $\begin{array}{l}\text { Proteins disrupt the interaction between DNA } \\
\text { and AuNPs, or fluorophore/enzyme and NPs, } \\
\text { or surfactant and AuNPs. }\end{array}$ & $\begin{array}{l}\text { The optical properties could be } \\
\text { well-modulated by changing the size, } \\
\text { shape, surface modification or aggregation } \\
\text { state of the AuNPs. }\end{array}$ & $\begin{array}{l}\text { Gold is a high-cost metal and the } \\
\text { construction of such arrays is complex } \\
\text { due to the introduction of DNA } \\
\text { fluorophores, or surfactants. }\end{array}$ \\
\hline
\end{tabular}

sensor arrays for proteins were also constructed by changing the $\mathrm{pH}$ values and ionic strengths because different proteins usually have different net surface charges, such as negative, positive, or neutral at various $\mathrm{pH}$. Xu et al. (2010) created an array of water-soluble conjugated polymer solutions with six different ionic strengths for protein identification and denaturation detection. The conjugated polymer could form complexes with proteins via electrostatic or hydrophobic interactions, which exhibited different fluorescent responses. Results suggested that the ionic strength of testing solution could affect the electrostatic interaction and protein aggregation. Thus, this sensor array could identify seven different proteins and also detect denaturation of proteins.

The discrimination of post-translational modifications (PTMs) in proteins has attracted widespread attention in the elucidation of human diseases as well as therapeutic protein improvements (Venne et al., 2014; Pagel et al., 2015; Dumont et al., 2016). Tomita et al. (2017) reported a novel strategy based on a poly-L-lysine (PLL-Dnc) derivative modified with environment-sensitive dansyl fluorophore for fingerprinting protein populations with PTMs. They used this single PLL-Dnc polymer at six different $\mathrm{pH}$ values and ionic strengths to construct a sensor array for successfully distinguishing proteins (Figure 8). It was not only capable of identifying four mammalian serum albumins (HSA, BSA, ESA, and RSA), but also separating the protein populations with/without PTMs (phosphorylated, glycated, methylated, and acetylated proteins). This is the first work for applying a single synthetic polymer to discriminate multiple proteins with/without PTMs. In order to promote the application of this system in detecting proteins secreted by cultured cells, the same group studied the ability of PLL-Dnc to recognize hepatocyte-derived secreted proteins incorporated into culture media (Sugai et al., 2019). An array of PLL-Dnc in six different buffer solutions could successfully recognize five secretory proteins ( $\alpha_{1}$-antitrypsin, albumin, transferrin, fibrinogen, and $\alpha$-fetoprotein) in culture media with $100 \%$ accuracy. This work proved the solution-condition-dependent discrimination of proteins spiked into the culture medium, rendering such an environment-sensitive system a potential sensor platform for evaluation of cultured cells.

In addition, $\mathrm{pH}$-based sensor arrays using QDs or Au NCs were also developed. Yan et al. (2019) reported a sensor array containing negatively charged QDs as an indicator for protein discrimination in different $\mathrm{pH}$ buffer solutions. The results illustrated that proteins with different isoelectric points $(\mathrm{pI}<$ 7 , $\mathrm{pI}=7$, or $\mathrm{pI}>7$ ) could be differentiated successfully. It is known that $\mathrm{pI}$ is defined as the $\mathrm{pH}$ value at which a protein has no net charge. A protein possesses net negative (positive) surface charge when $\mathrm{pH}$ is above (below) its $\mathrm{pI}$, and thus has different electrostatic interactions with QDs, which contributes to the differentiation of different proteins. Furthermore, this sensor array was able to identify complex protein mixtures and HSA at different concentrations in water and urine. Subsequently, Xu et al. (2019) synthesized a type of $\mathrm{Au}$ NCs coated with screened peptides of specific sequences, and developed a sensor array with different positive or negative charges through adjusting $\mathrm{pH}$ values $(\mathrm{pH} 1.5,3.5,6.0,10.0$, and $11.5)$. This sensor array could identify not only 10 proteins, but also protein mixtures with diverse components. Furthermore, a total of 50 unknown proteins could be effectively discriminated in human urine with $100 \%$ accuracy, and serums from rectal cancer patients, severe osteoarthritis patients, breast cancer patients and healthy people could be well-identified, suggesting possible potential application in auxiliary diagnosis. So far, the environment-sensitive sensor arrays for proteins have been constructed only by adjusting $\mathrm{pH}$ values and ionic strengths. Therefore, it is urgent to develop novel types of environmentalsensitive sensor array, for example, by changing the viscosity, polarity, etc. 

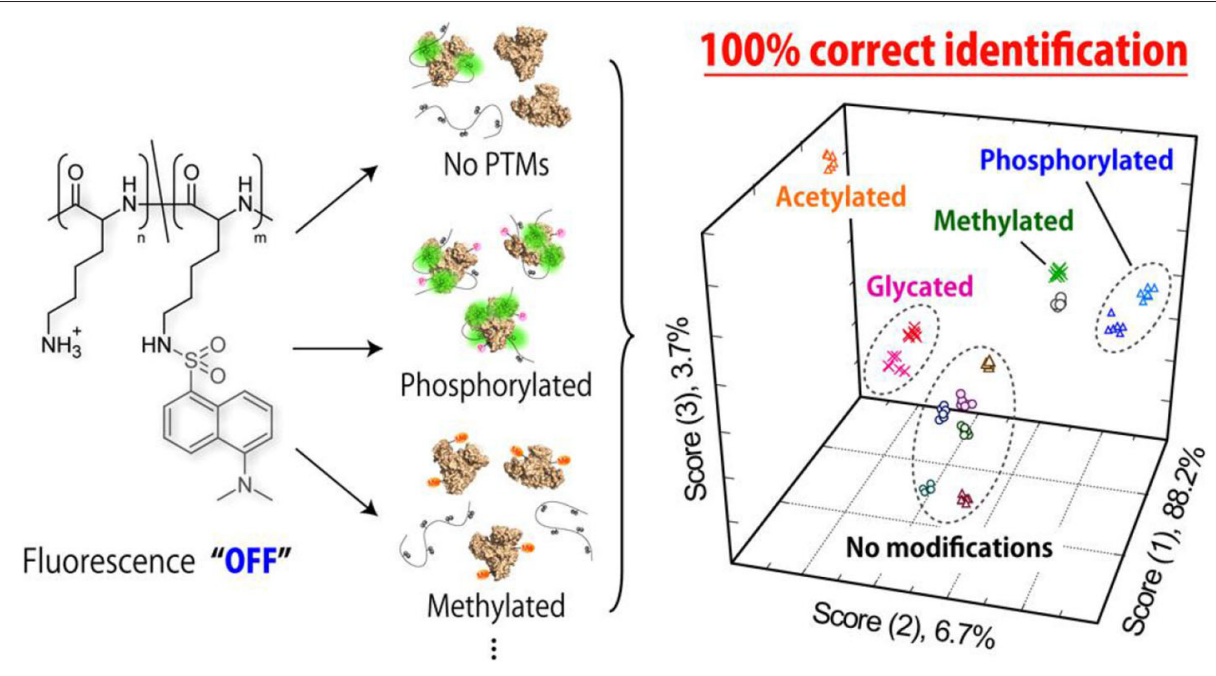

FIGURE 8 | Schematic illustration of fluorogenic interactions with proteins with/without PTMs. Reprinted from Tomita et al. (2017) with permission.

\section{MULTI-WAVELENGTH-BASED SINGLE SENSING SYSTEM FOR PROTEIN RECOGNITION}

The key to develop multi-wavelength-based single system is to provide diverse signal variations at different wavelengths, where this system can generate distinct response patterns to various analytes at an array of channels (Lu et al., 2013a; Sang and Wang, 2014; Long et al., 2020) or emission bands (Kstereli et al., 2014; Hatai et al., 2017). Thus, this kind of sensing system can be divided into multi-channel sensors and multi-band emission sensors.

\section{Multi-Channel Sensors}

Multi-channel sensors have attracted much more attention because they can extract multidimensional signals from an individual multifunctional sensor element, which is called "labon-a-molecule" or "lab-on-a-nanoparticle" (Wu et al., 2011; Yang B. et al., 2014). Multiple signal transduction, such as UV-vis absorbance, fluorescence (FL), phosphorescence (Ph), electrogenerated chemiluminescence (ECL), light scattering (LS), electrochemical (EC), turbidity and so forth, have been involved into nanoparticles or graphene oxide for multi-channel sensing (Liu et al., 2010; Hu et al., 2011; Wu et al., 2013). Up to now, a lot of dual-channel, triple-channel, and quadruple-channel sensors have been widely developed for protein identification.

For dual-channel sensors, Ma et al. (2017) have established a fluorescent sensor based on light-induced self-assembly behavior of bi-color thioglycolic acid-capped CdTe QDs (green and yellow emitting QDs, i.e., G-QDs and Y-QDs), which were prepared by simply modulating the reaction time (90 and $105 \mathrm{~min}$ ). The added proteins and CdTe QDs could form CdTeprotein complex which would further influence the self-assembly behavior of CdTe QDs and result in diverse changes of FL signals (Figure 9). This dual-channel sensor was successfully applied

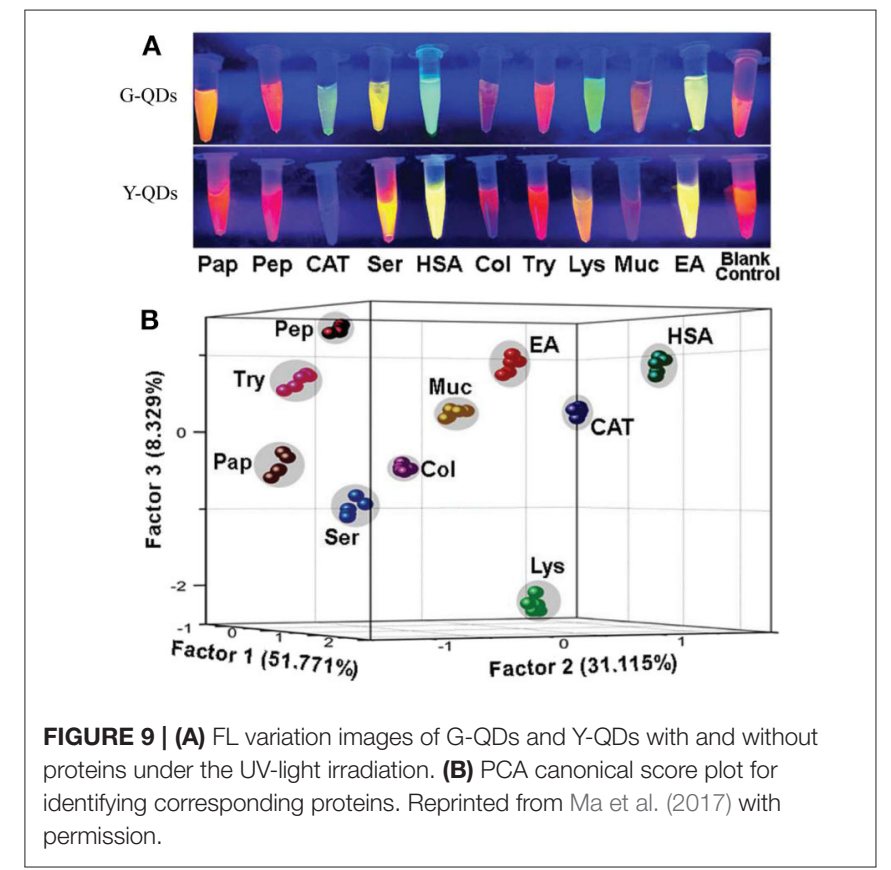

for discrimination of 10 native proteins, 10 thermally denatured proteins, and 8 native proteins in urine. This study has provided a simple and visual method for protein identification, which may be further applied in studying the conformational changes of biomacromolecules.

For triple-channel sensors, they are very popular and have been largely used to construct protein sensors based on different materials. Lu et al. (2013a) found that graphene oxide could interact with proteins and affect its fluorescence, catalytic activity and assembly behavior. Thus, a triple-channel optical sensor (fluorescence, colorimetric and turbidity) was proposed for protein discrimination in a "lab-on-graphene" manner. Six 
different proteins, unknown samples and protein mixtures were all well-distinguished by LDA with $100 \%$ accuracy, respectively. Considering the good biocompatibility and variety of graphenebased materials, this study will broaden the potential application fields of graphene-based materials.

The Liu group fabricated a triple-channel colorimetric sensor based on DNA-AuNP conjugates (A21-AuNPs) for protein discrimination (Mao et al., 2016). The triple-channel signals are composed of salt-induced aggregation (color 1), $\mathrm{HAuCl}_{4}$-induced AuNP regrowth (color 2) and protein-triggered aggregation (color 3) (Figure 10). Different proteins have diverse degrees of disruption of the interaction between DNA and AuNPs, which could make the response signals change differently. Thus, such a sensor was able to effectively identify 13 proteins, BSA and HSA mixtures, unknown samples and proteins in urine with an accuracy of $100 \%$. They also developed another triple-channel colorimetric sensor by collecting the absorbance signals at three different reaction time points (10, 15, and $20 \mathrm{~min})$ (Yang et al., 2017). Ten proteins in both aqueous solution and human urine were discriminated with 100\% accuracy. Moreover, this optosensing system could quantitatively detect HSA and identify mixtures of HSA and Lys at different molar ratios in urine. This assay illustrated the use of real-time resolved response signals could increase the recognition ability for protein discrimination.

QDs are also applied for constructing multi-channel sensors by collecting the signal changes of one type of QDs at different channels. Wu et al. (2011) reported a triple-channel sensing device based on the optical intensities of FL, LS, and $\mathrm{Ph}$ of $\mathrm{Mn}-\mathrm{ZnS}$ QDs for protein discrimination. Distinct recognition patterns related to eight proteins can be generated by collecting the three response signals of this triple-channel sensor. This sensor was further applied for identification of proteins in human urine to demonstrate its potential application. Sang and Wang (2014) also constructed a triple-channel sensor based on MnZnS QDs for 10 glycoprotein identification by utilizing the fluorescence polarization (FP), Ph, and LS signals. The tested 10 glycoproteins could be well-distinguished in PBS buffer and human serum. Besides, the accuracy of identifying unknown samples was above $96 \%$.

Then, Xu et al. (2016) have built a triple-channel sensor containing three spectral resolvable streptavidin (SA)-QDs (QD525, QD585, and QD655) and a quencher (bromophenol blue, BPB) in a single solution (Figure 11A). The quencher $\mathrm{BPB}$ could non-covalently bind with QDs to form QD-BPB complex, inducing fluorescence quenching of QDs. The addition of proteins disrupted the QD-BPB complex, leading to the separation of BPB from QDs and the fluorescence recovery of QDs (Figure 11B). This sensing platform excited at a singlewavelength allows for the correct identification of 10 proteins with very rapid response time (within $1 \mathrm{~min}$ ). Moreover, it can apply in discrimination of proteins in serum and recognition of seven cell lines (one normal human cell line and six cancerous cell lines) based on the different cell surface proteins, suggesting great potential for fast and high-throughput medical diagnostics.

For quadruple-channel sensors, Li et al. (2016) constructed a sensing device including the intrinsic fluorescence (IF) of proteins and the triple-channel optical output of Mn-ZnS QDs (FL, Ph, and LS) (Figure 12). They found that the introduction of IF as the fourth channel could dramatically improve the protein discrimination resolution. To further enhance the crossreactivity of the sensor, they applied dielectric barrier discharge plasma for protein modification to increase the IF difference of proteins as well as interactions between proteins and QDs. This sensor could precisely distinguish 12 diverse proteins, mixed serum proteins, and physiologically relevant proteins in human serum and urine with $100 \%$ accuracy. Furthermore, it could discriminate three different kinds of cell lines including human normal cell, cancerous cell, and mouse metastatic cell. The developed multi-channel sensors are mainly based on QDs, AuNPs, and graphene oxide. In contrast, the development of triple-channel sensors is relatively rapid. The challenge of this type of sensor is to find new materials and develop lowchannel sensors.

\section{Multi-Band Emission Sensors}

Multi-band emission sensors are sensors that perform discriminative sensing based on signal changes at different emission wavelengths. The Margulies group put forward the concept of combinatorial fluorescent molecular sensor which was obtained by introducing several fluorescent units with various emission bands and different recognition units into the same molecular structure. The binding of different analytes caused distinct changes at different wavelengths, consequently resulting in distinguishable signatures (Rout et al., 2012, 2013; Sarker et al., 2016). In 2017, they designed and synthesized a unimolecular fluorescent probe containing four partially spectrally overlapping fluorescent dyes (nitrobenzoxadiazole, Nile red, cyanine 5.5, and cyanine 7) and three specific binders for different protein families (Pode et al., 2017). This probe can overcome the shortcomings of some current probes that are less suitable for analyzing specific protein populations in their natural environment. It could not only identify different proteins, but also discriminate combinations of protein families in complex mixtures. More importantly, it could distinguish among isoforms in living cells that are inaccessible to macroscopic arrays.

Using the surfactant encapsulating and modulating effect, our group has fabricated a series of multi-wavelength-based cross-reactive sensors for protein identification by designing a fluorescent probe with multi-band emission (pyrene, perylene, etc.) and introducing surfactant aggregates to tune their fluorescence emission. In our first try, we prepared a binary fluorescent ensemble based on a neutral bispyrene-based fluorophore and cationic surfactant dodecyltrimethylammonium bromide (DTAB) assemblies (Fan et al., 2015). The presence of DTAB assemblies in different aggregation states could efficiently adjust the emission of bispyrene probe from excimer-dominated emission to monomer-excimer co-emission until to monomerdominated emission (Figure 13A). Protein sensing studies illustrated that the ensemble with monomer-excimer co-emission could exhibit ratiometric responses to non-metalloproteins and quenching responses to metalloproteins. The collection of fluorescence variations at monomer and excimer emission wavelengths could generate different recognition patterns to 


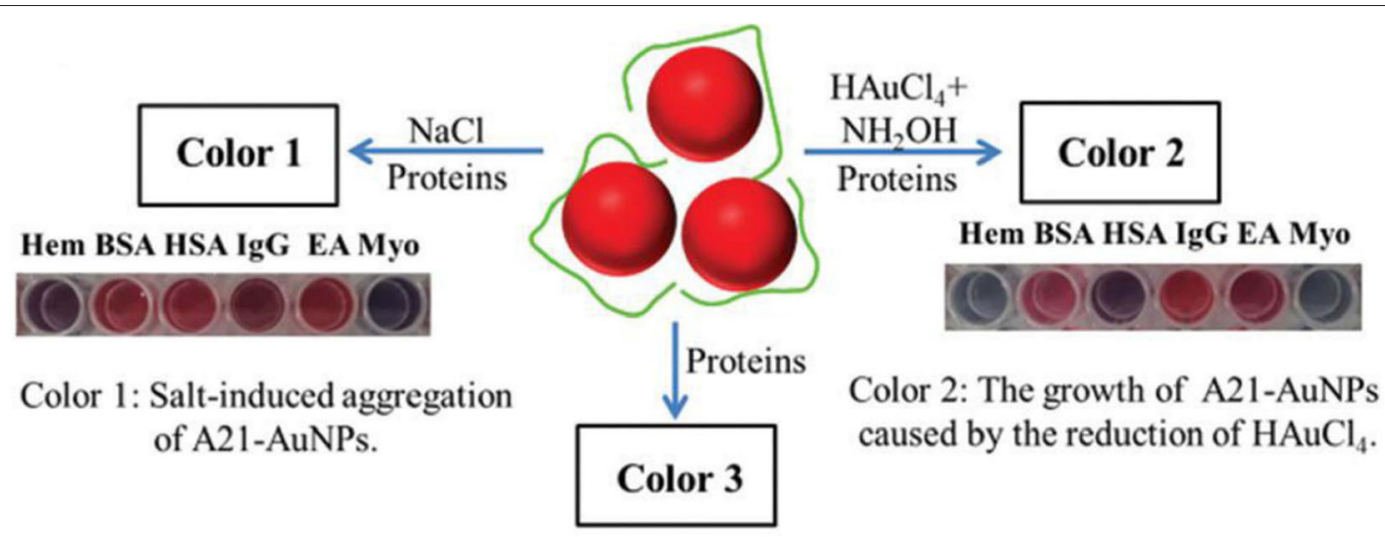

Hem BSA HSA IgG EA Myo

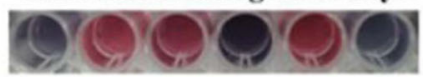

Color 3: The assembly of A21-AuNPs caused by proteins.

AuNPs ssDNA

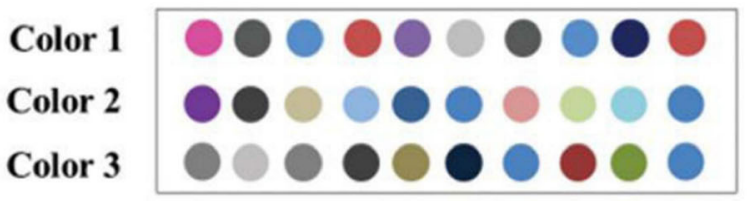

Colorimetric pattern

FIGURE 10 | Schematic representation of the triple-channel A21-AuNPs for protein sensing and the produced colorimetric pattern. Reprinted from Mao et al. (2016) with permission.

negatively-charged non-metalloproteins, positively-charged non-metalloproteins and metalloproteins, and then realize the differentiation among the three types of proteins (Figure 13B). The ratiometric responses to non-ometalloproteins were attributed to protein-induced further aggregation of the binary ensemble, while the turn-off responses to metalloproteins were ascribed to the energy/electron transfer from the ensemble to proteins. We also found the polarity of the spacer between the two pyrene units played important roles in the process of realizing cross-reactive sensing of proteins.

In order to further identify the proteins belong to the same type, we developed a mini sensor array (Cao et al., 2016) and a single-sensor based discriminative system, which realized the identification of metalloproteins (Zheng et al., 2017). In the single-sensor system, our group have synthesized a mono-pyrene derivative containing a pyridine boronic acid unit to provide glycoprotein receptors and positive charges and a cholic acid group with self-assembly ability to increase the modulation effect by surfactant. The anionic surfactant, sodium dodecylbenzene sulfonate (SDBS), could well modulate the probe to emit multiband emission. Besides, the selected binary ensemble provided unique recognition patterns for seven metalloproteins including glycoproteins by collecting four emission wavelengths (381, $401 \mathrm{~nm}$ for pyrene monomer emission, $421 \mathrm{~nm}$ for distorted excimer emission, and $498 \mathrm{~nm}$ for perfect excimer emission) (Figure 14A), and it showed good discrimination capability of proteins by PCA (Figure 14B). What's more, this ensemble sensor can also well distinguish proteins in serum and urine, suggesting there is great potential for practical applications.

To check the feasibility of the multi-wavelength crossreactive strategy in identifying both non-metalloproteins and metalloproteins, we have designed a dual-fluorophore probe (bispyrene-modified perylene derivative) to provide more emission bands and signals. The cationic CTAB assemblies could effectively regulate the fluorescence emission of this dual-fluorophore probe from pyrene monomer emission to pyrene monomer-perylene co-emission (Bo et al., 2019). Just as we expected, the binary ensemble based on the dual-fluorophore probe and CTAB assemblies can provide fluorescence variation signals at six relative emission wavelengths (pyrene and perylene), which can generate a specific recognition pattern for a particular protein. Indeed, this single sensor can realize discrimination of four non-metalloproteins, four metalloproteins, unknown samples, and protein mixtures by LDA. In this study, the combination of a dual-fluorophore with multiple emission bands and the modulation effect of surfactant assemblies endows stronger discrimination ability for such binary ensemble sensors for proteins. 

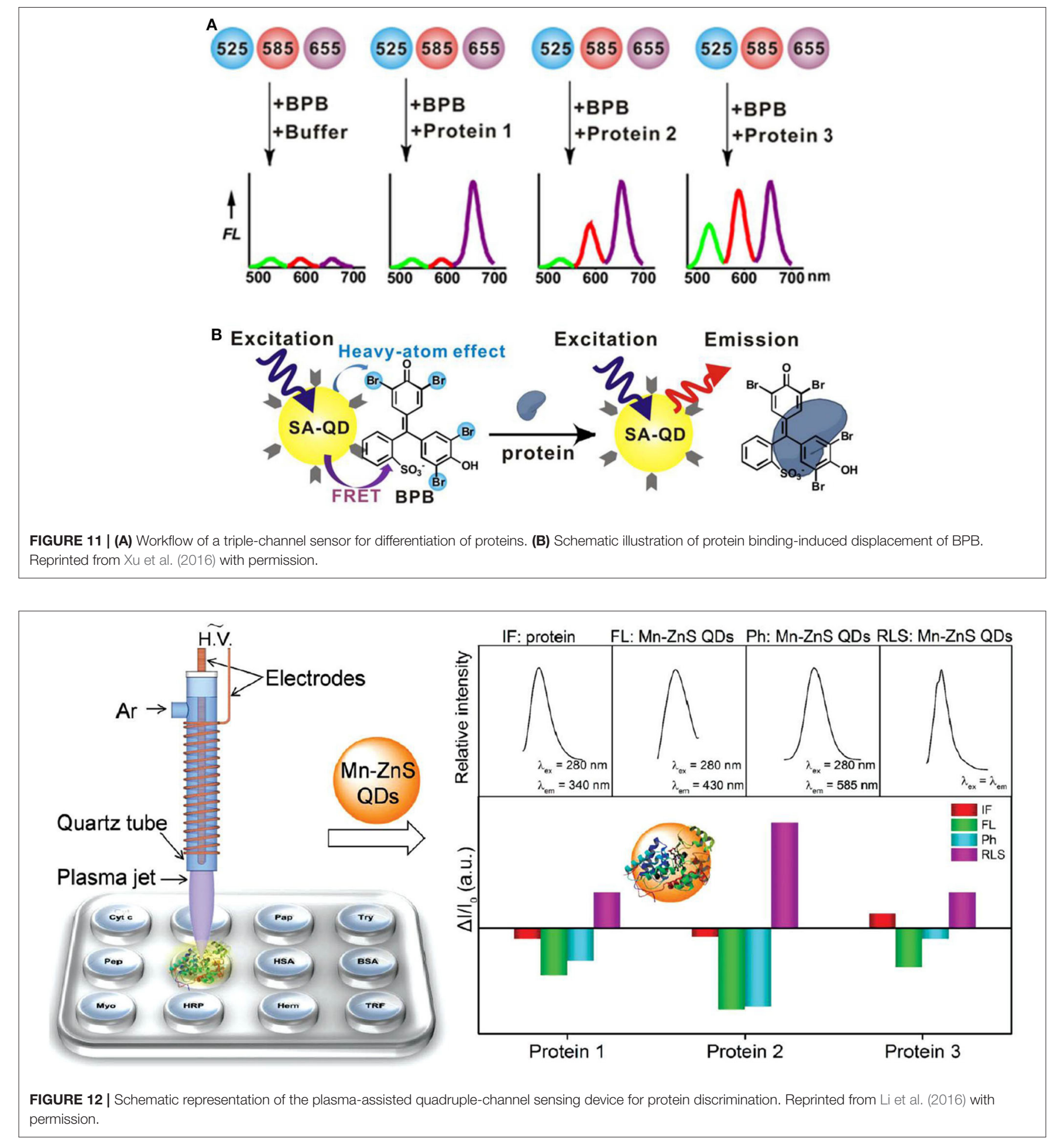

In addition, our group also synthesized an amphiphilic cholic acid-modified pyrene derivative, and found that it could form spherical aggregates and emit multiple fluorescence emission bands in aqueous solution (Fan et al., 2018). This fluorescent assembly showed ratiometric selective response to BSA or HSA among non-metalloproteins due to the disassembly of probe aggregates. But it showed turn-off response to four metalloproteins attributed to either electron or energy transfer from PyECA to bound metalloproteins. The different binding interactions of sensor platform and metalloproteins and the different contributions of two quenching mechanisms (electron or energy transfer) may be the reasons for the cross-reactive 

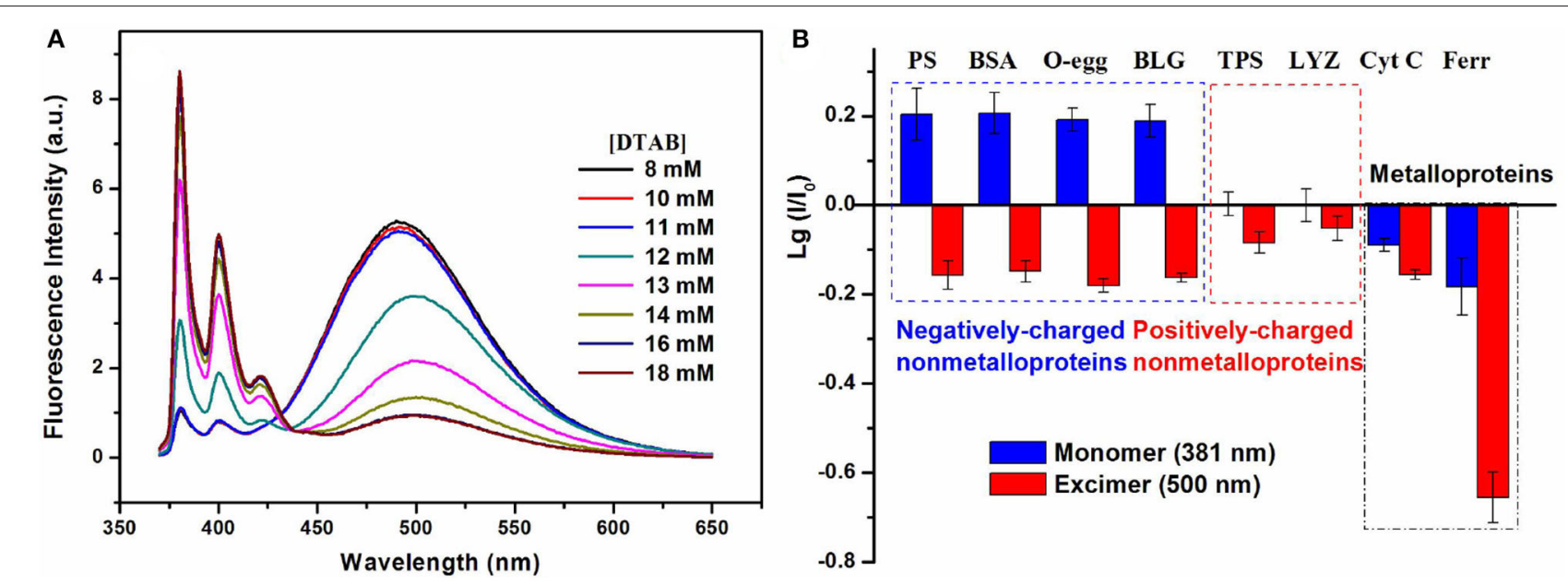

FIGURE 13 | (A) Fluorescence emission spectra of the bispyrene probe in different concentrated DTAB solutions. (B) Recognition patterns for different types of proteins. Reprinted from Fan et al. (2015) with permission.
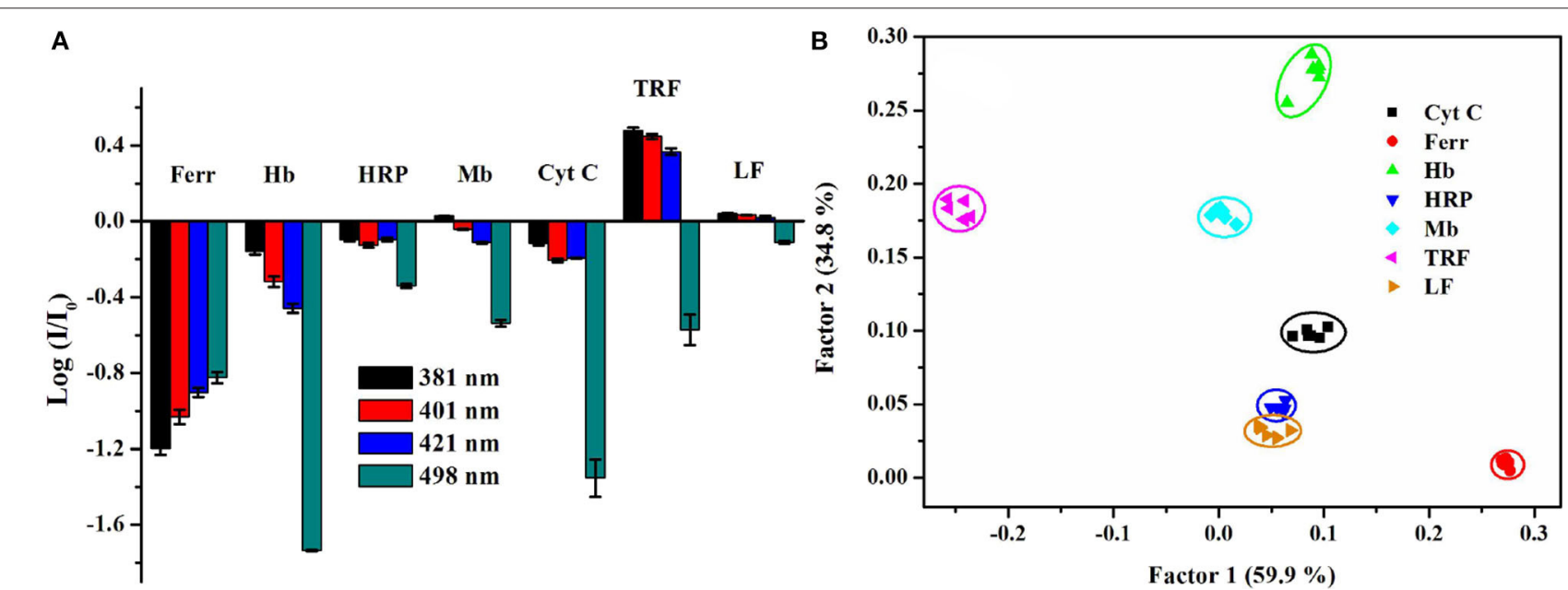

FIGURE 14 | (A) Recognition patterns for different types of metalloproteins. (B) PCA score plot for identifying metalloproteins at $0.5 \mu$ M. Reprinted from Zheng et al. (2017) with permission.

responses. This novel strategy is simple and can be extended to detect other analytes by using different supramolecular selfassemblies. Compared with multi-channel sensors, this type of sensors has outstanding advantages in data acquisition, because it only needs one scan of the emission spectrum to obtain the corresponding information. However, the biggest challenge of multi-band emission sensors is the high dependence on molecular design, which requires the introduction of multiple fluorophores or one fluorophore with multi-band emission.

\section{CONCLUSIONS AND OUTLOOK}

In this review, we focused on different optical sensor arrays for protein discrimination and their applications in real samples. The three strategies for constructing such sensor arrays including multi-element-based sensor arrays, environment-sensitive sensor arrays and multi-wavelength-based single sensing systems for protein discrimination were described in detail. Besides, we tried to explain the connections and differences among different strategies.

Each type of array has its own advantages and disadvantages. For a multi-element-based sensor array, a series of sensor elements are usually required, and sometimes the number of sensor elements is even more than the number of analytes, making such arrays more complicated and time-consuming in the process of construction and data collection. But the recognition ability of this type of sensor array is easy to improve by increasing the sensor elements. The environment-sensitive sensor array is constructed by adjusting $\mathrm{pH}$, polarity, viscosity, etc., and the multi-wavelength-based single system is based on an array of channels or emission bands, resulting in less dependent on design and synthesis of various probes (only one probe) 
compared with multi-element-based sensor arrays. Moreover, the third strategy using one single sensor system could significantly decrease sample consumption and simplify the data collection process. By comparison, the three types of sensor arrays have their own drawbacks. The construction and sensing process of the first type of array is the most time-consuming and costly, the second type of array is the most environment-sensitive and the least expandable, and the third type has highest requirements for the molecule design and instruments.

Although these three types of array-based sensors are different, they are closely related. For example, quantum dots (QDs) are involved in all three types but play different roles. In the first type, a variety of QDs are mainly used as sensor elements. But the second type involves only one type of QDs and the sensor elements are constructed by changing $\mathrm{pH}$ and ionic strengths. For the third type, the simplest one, the discrimination is achieved by collecting the signal changes of one type of QDs at different channels. It seems to be repetitive and unreasonable, but they actually serve their respective classifications very well.

Up to now, multi-element-based sensor arrays for protein identification have been boomingly developed, especially arrays constructed by nanomaterials as building blocks. The ability to realize strong discrimination ability of this type of sensor arrays based on as few as sensor elements is the big challenge and the future development trend. There have been some reports that realized using only two or three elements to achieve high-throughput detection of proteins. The other two types of optical biosensors have been relatively slowly developed. The challenge for the second type of environment-sensitive ones is the deep understanding of photophysical properties of a particular probe on the environments and design of new structural and effective probes. The development for the

\section{REFERENCES}

Bajaj, A., Miranda, O. R., Kim, I., Phillips, R. L., Jerry, D. J., Bunz, U. H. F., et al. (2009). Detection and differentiation of normal, cancerous, and metastatic cells using nanoparticle-polymer sensor arrays. Proc. Natl. Acad. Sci. U.S.A. 106, 10912-10916. doi: 10.1073/pnas.0900975106

Bajaj, A., Rana, S., Miranda, O. R., Yawe, J. C., Jerry, D. J., Bunz, U. H. F., et al. (2010). Cell surface-based differentiation of cell types and cancer states using a gold nanoparticle-GFP based sensing array. Chem. Sci. 1, 134-138. doi: $10.1039 / \mathrm{c} 0$ sc00165a

Bakalova, R., Ohba, H., Zhelev, Z., Nagase, T., Jose, R., Ishikawa, M., et al. (2004). Quantum dot anti-CD conjugates: are they potential photosensitizers or potentiators of classical photosensitizing agents in photodynamic therapy of cancer? Nano Lett. 4, 1567-1573. doi: 10.1021/nl049627w

Bigdeli, A., Ghasemi, F., Golmohammadi, H., Abbasi-Moayed, S., Farahmandnejad, M. A., Fahimi-Kashani, N., et al. (2017). Nanoparticle-based optical sensor arrays. Nanoscale 9, 16546-16563. doi: 10.1039/C7NR03311G

Bo, Y., Fan, J., Yan, S., Ding, M., Liu, J., Peng, J., et al. (2019). Surfactant modulation effect on the fluorescence emission of a dual-fluorophore: Realizing a single discriminative sensor for identifying different proteins in aqueous solutions. Sensor Actuat. B Chem. 295, 168-178. doi: 10.1016/j.snb.2019.05.078

Boeneman, K., Delehanty, J. B., Susumu, K., Stewart, M. H., and Medintz, I. L. (2010). Intracellular bioconjugation of targeted proteins with semiconductor quantum dots. J. Am. Chem. Soc. 132, 5975-5977. doi: 10.1021/ja100201w

Cao, J., Ding, L., Hu, W., Chen, X., Chen, X., and Fang, Y. (2014). Ternary system based on fluorophore-surfactant assemblies- $\mathrm{Cu}^{2+}$ for highly sensitive and third type of multiple-wavelength cross-reactive single-system is highly dependent on the molecular design, which makes this type of sensor array grow slowly. But these two types also have broad application prospects because of easy preparation and simple data collection process. Particularly, the third type is more attractive due to the easy data collection and less consumption of samples. The aid of supramolecular assemblies on modulating photophysical properties of fluorescent probes makes this strategy more feasible. This type of optical sensor arrays will become a hot trend for developing discriminative sensors for proteins and other analytes.

\section{AUTHOR CONTRIBUTIONS}

JF and LQ designed and wrote the manuscript. $\mathrm{HH}$ and LD revised the manuscript. All authors listed have made a substantial, direct and intellectual contribution to the work, and approved it for publication.

\section{FUNDING}

The authors appreciate the financial support from National Natural Science Foundation of China (21972086), the Fundamental Research Funds for the Central Universities (GK202001005), and the Program of Introducing Talents of Discipline to Universities (B14041). We also acknowledge the support from The Youth Innovation Team of Shaanxi Universities, the Scientific and Technological Innovation Programs of Higher Education Institutions in Shanxi (201802098, 2019L0818, and 2020L0504), the College Student's Innovation Fund of Shanxi Province (2020496), and Taiyuan Normal University (CXCY2002). selective detection of arginine in aqueous solution. Langmuir 30, 15364-15372. doi: 10.1021/la5039798

Cao, Y., Ding, L., Hu, W., Peng, J., and Fang, Y. (2014a). A surfactantmodulated fluorescent sensor with pattern recognition capability: sensing and discriminating multiple heavy metal ions in aqueous solution. J. Mater. Chem. A 2, 18488-18496. doi: 10.1039/C4TA03608E

Cao, Y., Ding, L., Wang, S., Liu, Y., Fan, J., Hu, W., et al. (2014b). Detection and identification of $\mathrm{Cu}^{2+}$ and $\mathrm{Hg}^{2+}$ based on the cross-reactive fluorescence responses of a dansyl-functionalized film in different solvents. ACS Appl. Mater. Interfaces 6, 49-56. doi: 10.1021/am405157k

Cao, Y., Zhang, L., Huang, X., Xin, Y., and Ding, L. (2016). Discrimination of metalloproteins by a mini sensor array based on bispyrene fluorophore/surfactant aggregate ensembles. ACS Appl. Mater. Interfaces 8, 35650-35659. doi: 10.1021/acsami.6b12646

Cao, Z., Fan, X., Yang, Z., Zhang, X., Ding, N., Ding, Y., et al. (2020). Solvent directed discrimination of metal ions using a coumarin-pyridine fluorescence receptor. Sensor Actuat. B Chem. 310, 127855-127860. doi: 10.1016/j.snb.2020.127855

Chang, N., Lu, Y., Mao, J., Yang, J., Li, M., Zhang, S., et al. (2016). Ratiometric fluorescence sensor arrays based on quantum dots for detection of proteins. Analyst 141, 2046-2052. doi: 10.1039/C5AN0 $2545 \mathrm{~A}$

Chen, F., and Gerion, D. (2004). Fluorescent CdSe/ZnS nanocrystalpeptide conjugates for long-term, nontoxic imaging and nuclear targeting in living cells. Nano Lett. 4, 1827-1832. doi: 10.1021/nl04 $9170 \mathrm{q}$ 
Chen, S., Li, Y., and Li, Y. (2013). Architecture of low dimensional nanostructures based on conjugated polymers. Poly. Chem. 4, 5162-5180. doi: 10.1039/c3py0 $0098 \mathrm{~b}$

Chen, S., Wei, L., Chen, X., and Wang, J. (2015). Suspension-array of ionic liquid or ionic liquid-quantum dots conjugates for the discrimination of proteins and bacteria. Anal. Chem. 87, 10902-10909. doi: 10.1021/acs.analchem.5b02453

Choi, H., Kim, S., Lee, S., Kim, C., and Ryu, J. H. (2018). Array-based protein sensing using an aggregation-induced emission (AIE) light-up probe. ACS Omega 3, 9276-9281. doi: 10.1021/acsomega.8b01269

Daly, M. L., Kerr, C., Derosa, C. A., and Fraser, C. L. (2017). Metaalkoxy-substituted difluoroboron dibenzoylmethane complexes as environment-sensitive materials. ACS Appl. Mater. Interfaces 9, 32008-32017. doi: 10.1021/acsami.7b06910

Daniel, M. C., and Astruc, D. (2004). Gold nanoparticles: assembly, supramolecular chemistry, quantum-size-related properties, and applications toward biology, catalysis, and nanotechnology. Chem. Rev. 104, 293-346. doi: $10.1021 / \mathrm{cr} 030698+$

De, M., Rana, S., Akpinar, H., Miranda, O. R., Arvizo, R. R., Bunz, U. H. F., et al. (2009). Sensing of proteins in human serum using conjugates of nanoparticles and green fluorescent protein. Nat. Chem. 1, 461-465. doi: 10.1038/nchem.334

Ding, L., Wang, S., Liu, Y., Cao, J., and Fang, Y. (2013). Bispyrene/surfactant assemblies as fluorescent sensor platform: detection and identification of $\mathrm{Cu}^{2+}$ and $\mathrm{Co}^{2+}$ in aqueous solution. J. Mater. Chem. A 1, 8866-8875. doi: 10.1039/c3ta10453b

Dumont, J. A., Euwart, D., Mei, B., Estes, S., and Kshirsagar, R. (2016). Human cell lines for biopharmaceutical manufacturing: history, status, and future perspectives. Crit. Rev. Biotechnol. 36, 1110-1122. doi: 10.3109/07388551.2015.1084266

Fan, J., and Ding, L. (2018). Single-system based discriminative optical sensors: different strategies and versatile applications. Analyst 143, 3775-3788. doi: 10.1039/C8AN00235E

Fan, J., Ding, L., Bo, Y., and Fang, Y. (2015). Fluorescent ensemble based on bispyrene fluorophore and surfactant assemblies: sensing and discriminating proteins in aqueous solution. ACS Appl. Mater. Interfaces 7, 22487-22496. doi: 10.1021/acsami.5b06604

Fan, J., Ding, L., and Fang, Y. (2019). Surfactant aggregates encapsulating and modulating: an effective way to generate selective and discriminative fluorescent sensors. Langmuir 35, 326-341. doi: 10.1021/acs.langmuir.8b02111

Fan, J., Zheng, D., Huang, X., Ding, L., Xin, Y., and Fang, Y. (2018). A single discriminative sensor based on supramolecular self-assemblies of an amphiphilic cholic acid-modified fluorophore for identifying multiple proteins. Sensor Actuat. B Chem. 263, 336-346. doi: 10.1016/j.snb.2018.02.132

Feng, F., Liu, L., Yang, Q., and Wang, S. (2010). Water-soluble conjugated polymers for fluorescent-enzyme assays. Macromol. Rapid Commun. 31, 1405-1421. doi: 10.1002/marc.201000020

Galdeano, C., Viayna, E., Sola, I., Formosa, X., Camps, P., Badia, A., et al. (2012). Huprine-tacrine heterodimers as anti-amyloidogenic compounds of potential interest against Alzheimer's and Prion diseases. J. Med. Chem. 55, 661-669. doi: $10.1021 / \mathrm{jm} 200840 \mathrm{c}$

Gao, X., Chan, W. C. W., and Nie, S. (2002). Quantum-dot nanocrystals for ultrasensitive biological labeling and multicolor optical encoding. J. Biomed. Opt. 7, 532-537. doi: 10.1117/1.1506706

Geng, J., Goh, C. C., Tomczak, N., Liu, J., Liu, R., Ma, L., et al. (2014). Micelle/silica Co-protected conjugated polymer nanoparticles for two-photon excited brain vascular imaging. Chem. Mater. 26, 1874-1880. doi: 10.1021/cm4040374

Gonzalez, D. C., Savariar, E. N., and Thayumanavan, S. (2009). Fluorescence patterns from supramolecular polymer assembly and disassembly for sensing metallo- and nonmetalloproteins. J. Am. Chem. Soc. 131, 7708-7716. doi: $10.1021 /$ ja900579g

Hatai, J., Margulies, D., and Motiei, L. (2017). Analyzing amyloid beta aggregates with a combinatorial fluorescent molecular sensor. J. Am. Chem. Soc. 1, 2136-2139. doi: 10.1021/jacs.6b10809

Heuff, R. F., Swift, J. L., and Cramb, D. T. (2007). Fluorescence correlation spectroscopy using quantum dots: advances, challenges and opportunities. Phys. Chem. Chem. Phys. 9, 1870-1880. doi: 10.1039/b617115j

Hu, J., Jiang, X., Wu, L., Xu, K., and Lv, Y. (2011). UV-induced surface photovoltage and photoluminescence on $\mathrm{n}-\mathrm{Si} / \mathrm{TiO}_{2} / \mathrm{TiO}_{2}$ : Eu for dual-channel sensing of volatile organic compounds. Anal. Chem. 83, 6552-6558. doi: 10.1021/ac200 8459

Hu, R., Feng, J., Hu, D., Wang, S., Li, S., Li, Y., et al. (2010). A rapid aqueous fluoride ion sensor with dual output modes. Angew. Chem. Int. Ed. 49, 4915-4918. doi: 10.1002/anie.201000790

Jaiswal, J. K., Mattoussi, H., Mauro, J. M., and Simon, S. M. (2003). Long-term multiple color imaging of live cells using quantum dot bioconjugates. Nat. Biotechnol. 21, 47-51. doi: 10.1038/nbt767

Kong, H., Liu, D., Zhang, S., and Zhang, X. (2011). Protein sensing and cell discrimination using a sensor array based on nanomaterial-assisted chemiluminescence. Anal. Chem. 83, 1867-1870. doi: 10.1021/ac200076c

Kong, H., Lu, Y., Wang, H., Wen, F., Zhang, S., and Zhang, X. (2012). Protein discrimination using fluorescent gold nanoparticles on plasmonic substrates. Anal. Chem. 84, 4258-4261. doi: 10.1021/ac300718p

Kstereli, Z., Scopelliti, R., and Severin, K. (2014). Pattern-based sensing of aminoglycosides with fluorescent amphiphiles. Chem. Sci. 5, 2456-2460. doi: 10.1039/C4SC00737A

Kwak, K., Kumar, S. S., Pyo, K., and Lee, D. (2014). Ionic liquid of a gold nanocluster: a versatile matrix for electrochemical biosensors. ACS Nano 8, 671-679. doi: 10.1021/nn4053217

Li, C., Wu, P., and Hou, X. (2016). Plasma-assisted quadruple-channel optosensing of proteins and cells with Mn-doped ZnS quantum dots. Nanoscale 8, 4291-4298. doi: 10.1039/C5NR09130F

Li, H., Jia, M., Askim, J. R., Zhang, Y., Duan, C., Guan, Y., et al. (2014). An array sensor consisting of a single indicator with multiple concentrations and its application in ion discrimination. Chem. Commun. 50, 15389-15392. doi: 10.1039/C4CC07503J

Li, K., and Liu, B. (2010). Water-soluble conjugated polymers as the platform for protein sensors. Poly. Chem. 1, 252-259. doi: 10.1039/B9PY00283A

Li, L., Li, G., He, X., Yang, X., Liu, S., Tang, J., et al. (2018). Proteindriven disassembly of surfactant-polyelectrolyte nanomicelles: modulation of quantum dot/fluorochrome FRET for pattern sensing. Sensor Actuat. B Chem. 272, 393-399. doi: 10.1016/j.snb.2018.05.130

Lin, Q., Lu, T.-T., Zhu, X., Wei, T.-B., Li, H., and Zhang, Y.-M. (2016). Rationally introduce multi-competitive binding interactions in supramolecular gels: a simple and efficient approach to develop multi-analytes sensor array. Chem. Sci. 7, 5341-5346. doi: 10.1039/C6SC00955G

Lin, Y., Charchar, P., Christofferson, A. J., Thomas, M. R., Todorova, N., Mazo, M. M., et al. (2018). Surface dynamics and ligand-core interactions of quantum sized photoluminescent gold nanoclusters. J. Am. Chem. Soc. 140, 18217-18226. doi: 10.1021/jacs.8b04436

Lin, Z., Qu, Z., Chen, Z., Han, X., and Zhang, M. (2019). The marriage of protein and lanthanide: Unveiling a novel time-resolved fluorescence sensor array regulated by $\mathrm{pH}$ toward high-throughput assay of metal ions in biofluids. Anal. Chem. 91, 11170-11177. doi: 10.1021/acs.analchem.9b01879

Liu, D., Liu, M., Liu, G., Zhang, S., Wu, Y., and Zhang, X. (2010). Dual-channel sensing of volatile organic compounds with semiconducting nanoparticles. Anal. Chem. 82, 66-68. doi: 10.1021/ac902422s

Liu, Y., Mettry, M., Gill, A. D., Perez, L., Zhong, W., and Hooley, R. J. (2017). Selective heavy element sensing with a simple host: guest fluorescent array. Anal. Chem. 89, 11113-11121. doi: 10.1021/acs.analchem.7b03377

Long, Y., Liu, S., Cai, Y., Zhang, J., Zhang, X., and Tang, Y. (2020). A triple-channel sensing array for protein discrimination based on multi-photoresponsive g$\mathrm{C}_{3} \mathrm{~N}_{4}$. Microchim. Acta 187, 449-456. doi: 10.1007/s00604-020-04396-3

Lu, Y., Kong, H., Wen, F., Zhang, S., and Zhang, X. (2013a). Lab-on-graphene: graphene oxide as a triple-channel sensing device for protein discrimination. Chem. Commun. 49, 81-83. doi: 10.1039/C2CC37293B

Lu, Y., Liu, Y., Zhang, S., Wang, S., and Zhang, X. (2013b). Aptamer-based plasmonic sensor array for discrimination of proteins and cells with the naked eye. Anal. Chem. 85, 6571-6574. doi: 10.1021/ac4014594

Ma, L., Liu, H., Wu, G., Liu, Z., Wu, P., and Li, L. (2017). Light-induced selfassembly of bi-color CdTe quantum dots allows the discrimination of multiple proteins. J. Mater. Chem. B 5, 5745-5752. doi: 10.1039/C7TB00907K

Mansur, A. A. P., Mansur, H. S., Soriano-Araújo, A., and Lobato, Z. I. P. (2014). Fluorescent nanohybrids based on quantum dot-chitosan-antibody as potential cancer biomarkers. ACS Appl. Mater. Interfaces 6, 11403-11412. doi: 10.1021/am5019989 
Mao, J., Lu, Y., Chang, N., Yang, J., Yang, J., Zhang, S., et al. (2016). A nanoplasmonic probe as a triple channel colorimetric sensor array for protein discrimination. Analyst 141, 4014-4017. doi: 10.1039/C6AN00302H

Mattheakis, L. C., Dias, J. M., Choi, Y. J., Gong, J., Bruchez, M. P., Liu, J., et al. (2004). Optical coding of mammalian cells using semiconductor quantum dots. Anal. Biochem. 327, 200-208. doi: 10.1016/j.ab.2004.01.031

Michalet, X., Pinaud, F. F., Bentolila, L. A., Tsay, J. M., Doose, S., Li, J. J., et al. (2005). Quantum dots for live cells, in vivo imaging, and diagnostics. Science 307, 538-544. doi: 10.1126/science.1104274

Miranda, O. R., Chen, H., You, C., Mortenson, D. E., Yang, X., Bunz, U. H. F., et al. (2010). Enzyme amplified array sensing of proteins in solution and in biofluids. J. Am. Chem. Soc. 132, 5285-5289. doi: 10.1021/ja1006756

Miranda, O. R., You, C., Phillips, R. L., Kim, I., Ghosh, P., Bunz, U. H. F., et al. (2007). Array-based sensing of proteins using conjugated polymers. J. Am. Chem. Soc. 129, 9856-9857. doi: 10.1021/ja0737927

Nandu, N., Hizir, M. S., and Yigit, M. V. (2018). Systematic investigation of twodimensional DNA nanoassemblies for construction of a nonspecific sensor array. Langmuir 34, 14983-14992. doi: 10.1021/acs.langmuir.8b00788

Pagel, O., Loroch, S., Sickmann, A., and Zahedi, R. P. (2015). Current strategies and findings in clinically relevant post-translational modification-specific proteomics. Expert Rev. Proteomics 12, 235-253. doi: 10.1586/14789450.2015.1042867

Peveler, W. J., Yazdani, M., and Rotello, V. M. (2016). Selectivity and specificity: Pros and cons in sensing. ACS Sens. 1, 1282-1285. doi: 10.1021/acssensors.6b00564

Pode, Z., Peri-Naor, R., Georgeson, J. M., Ilani, T., Kiss, V., Unger, T., et al. (2017). Protein recognition by a pattern-generating fluorescent molecular probe. Nat. Nanotechnol. 12, 1161-1168. doi: 10.1038/nnano.2017.175

Rana, S., Elci, S. G., Mout, R., Singla, A. K., Yazdani, M., Bender, M., et al. (2016). Ratiometric array of conjugated polymers-fluorescent protein provides a robust mammalian cell sensor. J. Am. Chem. Soc. 138, 4522-4529. doi: 10.1021/jacs.6b00067

Rana, S., Singla, A. K., Bajaj, A., Elci, S. G., Miranda, O. R., Mout, R., et al. (2012). Array-based sensing of metastatic cells and tissues using nanoparticle-fluorescent protein conjugates. ACS Nano 6, 8233-8240. doi: $10.1021 / \mathrm{nn} 302917 \mathrm{e}$

Rogowski, J., Verma, M. S., and Gu, F. X. (2016). Discrimination of proteins using an array of surfactant-stabilized gold nanoparticles. Langmuir 32, 7621-7629. doi: 10.1021/acs.langmuir.6b01339

Rout, B., Milko, P., Iron, M. A., Motiei, L., and Margulies, D. (2013). Authorizing multiple chemical passwords by a combinatorial molecular keypad lock. J. Am. Chem. Soc. 135, 15330-15333. doi: 10.1021/ja4081748

Rout, B., Unger, L., Armony, G., Iron, M. A., and Margulies, D. (2012). Medication detection by a combinatorial fluorescent molecular sensor. Angew. Chem. Int. Ed. 51, 12477-12481. doi: 10.1002/anie.201206374

Sandanaraj, B. S., Demont, R., and Thayumanavan, S. (2007). Generating patterns for sensing using a single receptor scaffold. J. Am. Chem. Soc. 129, 3506-3507. doi: $10.1021 / \mathrm{ja} 070229 \mathrm{f}$

Sang, L. J., and Wang, H. F. (2014). Aminophenylboronic-acidconjugated polyacrylic acid-Mn-doped $\mathrm{ZnS}$ quantum dot for highly sensitive discrimination of glycoproteins. Anal. Chem. 86, 5706-5712. doi: $10.1021 /$ ac501020b

Sarker, T., Selvakumar, K., Motiei, L., and Margulies, D. (2016). Message in a molecule. Nat. Commun. 7:11374. doi: 10.1038/ncomms11374

Savariar, E. N., Ghosh, S., and Thayumanavan, S. (2008). Disassembly of noncovalent amphiphilic polymers with proteins and utility in pattern sensing. J. Am. Chem. Soc. 130, 5416-5417. doi: 10.1021/ja800164z

Scala, C. D., Yahi, N., Lelièvre, C., Garmy, N., Chahinian, H., and Fantini, J. (2013). Biochemical identification of a linear cholesterol-binding domain within Alzheimer's $\beta$ amyloid peptide. ACS Chem. Neurosci. 4, 509-517. doi: $10.1021 / \mathrm{cn} 300203 \mathrm{a}$

Smith, D. G., Mitchell, L., and New, E. J. (2019). Pattern recognition of toxic metal ions using a single-probe thiocoumarin array. Analyst 144, 230-236. doi: 10.1039/C8AN01747F

Stewart, S., Ivy, M. A., and Anslyn, E. V. (2013). The use of principal component analysis and discriminant analysis in differential sensing routines. Chem. Soc. Rev. 43, 70-84. doi: 10.1039/C3CS6 $0183 \mathrm{H}$
Sugai, H., Tomita, S., Ishihara, S., and Kurita, R. (2019). Fingerprint-based protein identification in cell culture medium using environment-sensitive turn-on fluorescent polymer. Sensor Mater. 31, 1-11. doi: 10.18494/SAM.2019.2032

Sun, M., Wu, L., Ren, H., Chen, X., Ouyang, J., and Na, N. (2017). Radical-mediated spin-transfer on gold nanoclusters driven an unexpected luminescence for protein discrimination. Anal. Chem. 89, 11183-11188. doi: 10.1021 /acs.analchem.7b02666

Sun, W., Lu, Y., Mao, J., Chang, N., Yang, J., and Liu, Y. (2015). Multidimensional sensor for pattern recognition of proteins based on DNA-gold nanoparticles conjugates. Anal. Chem. 87, 3354-3359. doi: 10.1021/ac504587h

Tao, Y., Ran, X., Ren, J., and Qu, X. (2014). Array-based sensing of proteins and bacteria by using multiple luminescent nanodots as fluorescent probes. Small 10, 3667-3671. doi: 10.1002/smll.201400661

Tomita, S., Ishihara, S., and Kurita, R. (2017). Environment-sensitive turn-on fluorescent polyamino acid: Fingerprinting protein populations with posttranslational modifications. ACS Appl. Mater. Interfaces 9, 22970-22976. doi: 10.1021/acsami.7b05360

Tyrakowski, C. M., and Snee, P. T. (2013). A primer on the synthesis, watersolubilization, and functionalization of quantum dots, their use as biological sensing agents, and present status. Phys. Chem. Chem. Phys. 16, 837-855. doi: 10.1039/C3CP53502A

Vazquez, M. E., Blanco, J. B., and Imperiali, B. (2005). Photophysics and biological applications of the environment-sensitive fluorophore 6- $\mathrm{N}, \mathrm{N}$-dimethylamino2,3-naphthalimide. J. Am. Chem. Soc. 127, 1300-1306. doi: 10.1021/ja0449168

Venne, A. S., Kollipara, L., and Zahedi, R. P. (2014). The next level of complexity: crosstalk of posttranslational modifications. Proteomics 14, 513-524. doi: 10.1002/pmic.201300344

Wang, K., Dong, Y., Li, B., Li, D., Zhang, S., and Wu, Y. (2017). Differentiation of proteins and cancer cells using metal oxide and metal nanoparticles-quantum dots sensor array. Sensor Actuat. B Chem. 250, 69-75. doi: 10.1016/j.snb.2017.04.152

Wang, X., Qin, L., Zhou, M., Lou, Z., and Wei, H. (2018). Nanozyme sensor arrays for detecting versatile analytes from small molecules to proteins and cells. Anal. Chem. 90, 11696-11702. doi: 10.1021/acs.analchem.8b03374

Wang, X., Zhao, X., Zheng, K., Guo, X., and Yan, Y. (2019). Ratiometric nanoparticle array-based near-infrared fluorescent probes for quantitative protein sensing. Langmuir 35, 5599-5607. doi: 10.1021/acs.langmuir.9b00788

Wei, X., Chen, Z., Tan, L., Lou, T., and Zhao, Y. (2017). DNA-catalytically active gold nanoparticle conjugates-based colorimetric multidimensional sensor array for protein discrimination. Anal. Chem. 89, 556-559. doi: 10.1021/acs.analchem.6b04878

$\mathrm{Wu}, \mathrm{D}$., and Schanze, K. S. (2014). Protein induced aggregation of conjugated polyelectrolytes probed with fluorescence correlation spectroscopy: Application to protein identification. ACS Appl. Mater. Interfaces 6, 7643-7651. doi: $10.1021 / \mathrm{am} 5009437$

Wu, P., Miao, L., Wang, H., Shao, X., and Yan, X. (2011). A multidimensional sensing device for the discrimination of proteins based on manganese-doped ZnS quantum dots. Angew. Chem. 123, 8268-8271. doi: 10.1002/ange.201101882

Wu, P., Zhao, T., Tian, Y., Wu, L., and Hou, X. (2013). Protein-directed synthesis of Mn-doped $\mathrm{ZnS}$ quantum dots: a dual-channel biosensor for two proteins. Chem. Eur. J. 19, 7473-7479. doi: 10.1002/chem.201204035

Xi, H., Li, X., Liu, Q., and Chen, Z. (2018). Cationic polymer-based plasmonic sensor array that discriminates proteins. Analyst 143, 5578-5582. doi: 10.1039/C8AN01360H

Xie, Y., Liu, Y., Yang, J., Liu, Y., and Jiang, X. (2018). Gold nanoclusters for targeting methicillin-resistant staphylococcus aureus in vivo. Angew. Chem. Int. Ed. 57, 3958-3962. doi: 10.1002/anie.201712878

Xu, Q., Wu, C., Zhu, C., Duan, X., Liu, L., Han, Y., et al. (2010). A water-soluble conjugated polymer for protein identification and denaturation detection. Chem. Asian J. 5, 2524-2529. doi: 10.1002/asia.201000363

Xu, Q., Zhang, Y., Tang, B., and Zhang, C. (2016). Multicolor quantum dot-based chemical nose for rapid and array-free differentiation of multiple proteins. Anal. Chem. 88, 2051-2058. doi: 10.1021/acs.analchem.5b03109

Xu, S., Gao, T., Feng, X., Fan, X., Liu, G., Mao, Y., et al. (2017). Near infrared fluorescent dual ligand functionalized Au NCs based multidimensional sensor array for pattern recognition of multiple proteins and serum discrimination. Biosens. Bioelectron. 97, 203-207. doi: 10.1016/j.bios.2017.06.007 
Xu, S., Li, W., Zhao, X., Wu, T., Cui, Y., Fan, X., et al. (2019). Ultrahighly efficient and stable fluorescent gold nanoclusters coated with screened peptides of unique sequences for effective protein and serum discrimination. Anal. Chem. 91, 13947-13952. doi: 10.1021/acs.analchem.9b03463

Xu, S., Lu, X., Yao, C., Huang, F., Jiang, H., Hua, W., et al. (2014). A visual sensor array for pattern recognition analysis of proteins using novel blue-emitting fluorescent gold nanoclusters. Anal. Chem. 86, 11634-11639. doi: $10.1021 /$ ac502643s

Yan, H., Cui, P., Liu, C., and Yuan, S. (2012). Molecular dynamics simulation of pyrene solubilized in a sodium dodecyl sulfate micelle. Langmuir 28, 4931-4938. doi: 10.1021/la300146s

Yan, P., Li, X., Dong, Y., Li, B., and Wu, Y. (2019). A pH-based sensor array for the detection and identification of proteins using $\mathrm{CdSe} / \mathrm{ZnS}$ quantum dots as an indicator. Analyst 144, 2891-2897. doi: 10.1039/C8AN02285B

Yan, X., Zhu, P., and Li, J. (2010). Self-assembly and application of diphenylalanine-based nanostructures. Chem. Soc. Rev. 39, 1877-1890. doi: 10.1039/b915765b

Yang, B., Zhang, X. B., Kang, L. P., Huang, Z. M., Shen, G. L., Yu, R. Q., et al. (2014). Intelligent layered nanoflare: "lab-on-a-nanoparticle" for multiple DNA logic gate operations and efficient intracellular delivery. Nanoscale 6, 8990-8996. doi: $10.1039 / \mathrm{C} 4 \mathrm{NR} 01676 \mathrm{~A}$

Yang, J., He, L., Lu, Y., Gao, X., Wang, F., Jing, W., et al. (2017). Acquiring multiple signals along with the reaction time: improving recognition capability of a multidimensional colorimetric sensor array for sensitive protein detection. Analyst 142, 2663-2669. doi: 10.1039/C7AN00660H

Yang, X., Li, J., Pei, H., Li, D., Zhao, Y., Gao, J., et al. (2013). Pattern recognition analysis of proteins using DNA-decorated catalytic gold nanoparticles. Small 9, 2844-2849. doi: 10.1002/smll.201202772

Yang, X., Li, J., Pei, H., Zhao, Y., Zuo, X., Fan, C., et al. (2014). DNA-gold nanoparticle conjugates-based nanoplasmonic probe for specific differentiation of cell types. Anal. Chem. 86, 3227-3231. doi: 10.1021/ac500381e

Yang, Z., Cao, J., He, Y., Yang, J. H., and Kim, J. S. (2014). Macro-/microenvironment-sensitive chemosensing and biological imaging. Chem. Soc. Rev. 43, 4563-4601. doi: 10.1039/C4CS00051J

You, C. C., Miranda, O. R., Gider, B., Ghosh, P. S., Kim, I. B., Erdogan, B., et al. (2007). Detection and identification of proteins using nanoparticlefluorescent polymer 'chemical nose' sensors. Nat. Nanotech. 2, 318-323. doi: 10.1038/nnano.2007.99

Yuan, Z., Du, Y., Tseng, Y. T., Peng, M., Cai, N., He, Y., et al. (2015). Fluorescent gold nanodots based sensor array for proteins discrimination. Anal. Chem. 87, 4253-4259. doi: 10.1021/ac5045302

Zhang, J., Mou, L., and Jiang, X. (2020). Surface chemistry of gold nanoparticles for health-related applications. Chem. Sci. 11, 923-936. doi: 10.1039/C9SC06497D
Zhang, J., Tu, L., Zhao, S., Liu, G., Wang, Y., Wang, Y., et al. (2015). Fluorescent gold nanoclusters based photoelectrochemical sensors for detection of $\mathrm{H}_{2} \mathrm{O}_{2}$ and glucose. Biosens. Bioelectron. 67, 296-302. doi: 10.1016/j.bios.2014.08.037

Zhang, L., Huang, X., Cao, Y., Xin, Y., and Ding, L. (2017). Fluorescent binary ensemble based on pyrene derivative and sodium dodecyl sulfate assemblies as a chemical tongue for discriminating metal ions and brand water. ACS Sens. 2, 1821-1830. doi: 10.1021/acssensors.7b00634

Zhang, S., Dong, Y., Wu, Y., Li, B., and Wang, K. (2015). Colorimetric sensor array with unmodified noble metal nanoparticles for naked-eye detection of proteins and bacteria. Analyst 140, 7672-7677. doi: 10.1039/C5AN01267H

Zhang, Z., Li, J., Wang, X., Shen, D., and Chen, L. (2015). Quantum dots based mesoporous structured imprinting microspheres for the sensitive fluorescent detection of phycocyanin. ACS Appl. Mater. Interfaces 7, 9118-9127. doi: 10.1021/acsami.5b00908

Zhao, B., Zhuang, J., Serrano, M. A. C., Vachet, R. W., and Thayumanavan, S. (2017). Influence of charge density on host-guest interactions within amphiphilic polymer assemblies in apolar media. Macromolecules 50, 6961-6966. doi: 10.1021/acs.macromol.7b02434

Zhao, L., Zhang, J., Xu, H., Geng, H., and Cheng, Y. (2016). Conjugated polymers/DNA hybrid materials for protein inactivation. ACS Appl. Mater. Interfaces 8, 22923-22929. doi: 10.1021/acsami.6b07803

Zheng, D., Fan, J., Huang, X., Ding, L., and Xin, Y. (2017). Fluorescent binary ensemble with pattern recognition ability for identifying multiple metalloproteins with applications in serum and urine. RSC Adv. 7, 50097-50105. doi: 10.1039/C7RA09741G

Zhou, X., Nie, J., and Du, B. (2017). Functionalized ionic microgel sensor array for colorimetric detection and discrimination of metal ions. ACS Appl. Mater. Interfaces 9, 20913-20921. doi: 10.1021/acsami.7b06337

Zhu, H., Fan, J., Wang, B., and Peng, X. (2015). Fluorescent, MRI, and colorimetric chemical sensors for the first-row d-block metal ions. Chem. Soc. Rev. 44, 4337-4366. doi: 10.1039/C4CS0 $0285 \mathrm{G}$

Conflict of Interest: The authors declare that the research was conducted in the absence of any commercial or financial relationships that could be construed as a potential conflict of interest.

Copyright (C) 2020 Fan, Qi, Han and Ding. This is an open-access article distributed under the terms of the Creative Commons Attribution License (CC BY). The use, distribution or reproduction in other forums is permitted, provided the original author(s) and the copyright owner(s) are credited and that the original publication in this journal is cited, in accordance with accepted academic practice. No use, distribution or reproduction is permitted which does not comply with these terms. 